\title{
Terapia Fotodinâmica ANTIMICROBiana (APDT) NO TRATAMENTo de Lesões Periapicais Induzidas EXPerimentalmente, em Dentes de CÃES
}

Tese apresentada à Faculdade de Odontologia de Ribeirão Preto da Universidade de São Paulo para obtenção do título de Doutor em Ciências. Programa: Odontopediatria Área de Concentração: Odontopediatria

Orientador: Prof. Dr. Arthur BelÉm Novaes Júnior Coorientadora: Profa. DR ${ }^{a}$. LÉa AsSed BeZERRA dA Silva

Ribeirão Preto 


\section{AUTORIZAÇÃo PARA REPRODUÇÃo}

Autorizo a reprodução e/ou divulgação total ou parcial da presente obra, por qualquer meio convencional ou eletrônico, desde que citada a fonte.

\section{Ficha Catalográfica}

Hidalgo, Lidia Regina da Costa

Terapia fotodinâmica antimicrobiana (aPDT) no tratamento de lesões periapicais induzidas experimentalmente, em dentes de cães. Ribeirão Preto, 2016.

120p. il.; $30 \mathrm{~cm}$

Tese de Doutorado, apresentada à Faculdade de Odontologia de Ribeirão Preto/USP - Área de Concentração: Odontopediatria.

Orientador: Novaes Jr, Arthur Belém

Coorientadora: Silva, Léa Assed Bezerra da

1. Lesão periapical 2. Terapia fotodinâmica antimicrobiana 3. Hidróxido de cálcio 


\section{FOLHA DE APROVAÇÃo}

Hidalgo, LRC. Terapia fotodinâmica antimicrobiana (aPDT) no tratamento de lesões periapicais induzidas experimentalmente, em dentes de cães.

Tese apresentada à Faculdade de Odontologia de Ribeirão Preto da Universidade de São Paulo, para obtenção do Título de Doutor em Ciências. Área de Concentração: Odontopediatria.

Data da defesa:

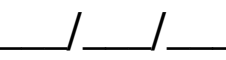

BANCA EXAMINADORA

Prof. Dr.

Julgamento Assinatura

Prof. Dr.

Julgamento Assinatura

Prof. Dr.

Julgamento Assinatura

Prof. Dr.

Julgamento Assinatura

Prof. Dr.

Julgamento Assinatura 



\section{LIDIA REGINA DA COSTA HIDALGO}

\section{Dados Curriculares}

Nascimento 09 de março de 1982 - Penápolis SP.

Filiação Maria Izabel da Costa Hidalgo

Vitalino Hidalgo

2004-2009

Curso de Graduação.

Faculdade de Odontologia de Araçatuba - Universidade Estadual Paulista Júlio de Mesquita Filho - FOA/UNESP

2005-2006

Iniciação Científica - Projeto de pesquisa intitulado "Saúde do trabalhador. Conduta das empresas frente aos atestados odontologicos" (Bolsa FAPESP).

2006-2007

Iniciação Científica - Projeto de pesquisa intitulado "Levantamento epidemiológico dos casos de câncer de boca diagnosticados após a implementação do Serviço Público de diagnóstico Bucal Mato Grosso entre os anos de 2005 e 2006" (Bolsa CNPq).

2007-2008

Iniciação Científica - Projeto de pesquisa intitulado "Conhecimento dos Cirurgiões Dentistas da rede pública de saúde dos municípios de Araçatuba e Presidente Prudente sobre Biossegurança" (Bolsa CNPq).

2008-2009

Iniciação Científica - Projeto de pesquisa intitulado "Gerenciamento de resíduos sólidos de Odontologia em unidades básicas de saúde nos municípios de Araçatuba e Penápolis" (Bolsa CNPq).

2010-2012

Curso de Pós-Graduação em Odontologia Preventiva e Social, nível Mestrado.

Faculdade de Odontologia de Araçatuba - Universidade Estadual Paulista Júlio de Mesquita Filho - FOA/UNESP - Dissertação intitulada "O descarte de lixo por profissionais da saúde e seu impacto sobre o meio ambiente" (Bolsa FAPESP).

2012-2016 Curso de Pós-Graduação em Odontopediatria, nível Doutorado.

Faculdade de Odontologia de Ribeirão Preto da Universidade de São Paulo - FORP/USP - Tese intitulada "terapia fotodinâmica antimicrobiana (aPDT) no tratamento de lesões periapicais induzidas experimentalmente, em dentes de cães" (Bolsa FAPESP). 

Trabalho desenvolvido nos Laboratórios de Histologia, Biologia Molecular e Cultura de Células do Departamento de Clínica Infantil da Faculdade de Odontologia de Ribeirão Preto - Universidade de São Paulo, com apoio financeiro da Fundação de Amparo à Pesquisa do Estado de São Paulo (FAPESP). Auxílio à Pesquisa (processo: 2012/14505-4) e Bolsa de Doutorado (processo: 2012/10238-1). 


\section{Saber Viver}

Compartilhar

Não sei se a vida é curta ou longa para nós,

mas sei que nada do que vivemos tem sentido,

se não tocarmos o coração das pessoas.

Muitas vezes basta ser:

colo que acolhe, braço que envolve, palavra que conforta, silêncio que respeita, alegria que contagia, lágrima que corre, olhar que acaricia, desejo que sacia, amor que promove.

E isso não é coisa de outro mundo, é o que dá sentido à vida.

É o que faz com que ela não seja nem curta, nem longa demais, mas que seja intensa, verdadeira, pura enquanto durar.

Feliz aquele que transfere o que sabe e aprende o que ensina.

(Cora Coralina) 
A Deus que se faz presente em meu caminho.

Agradeço pela presença incondicional em minha vida, que tanto me sustentou nos momentos de incertezas. Agradec,o por colocar tantas pessoas boas em meu caminho. Agradeço pela família linda que tenho e por todas as oportunidades que tem me dado. Agradec,o, sobretudo, pela oportunidade de estar nesse mundo aprendendo.

A minha querida Mãe Izabel,

Pelo exemplo de garra e força. Por todo suporte que me possibilitou superar diversas dificuldades, sendo sempre minha eterna incentivadora.

Agradeço pelas palavras positivas que sempre me fazem crer que eu posso ir além. Agradeço pelo amor, pela dedicação e por se fazer sempre presente.

MUITO OBRIGADO!

Ao meu Pai Vitalino, pelo amor, por me ensinar a acreditar nos meus sonhos e a nunca desistir das coisas. Você é muito especial.

Aos meus irmãos Lilian e Mateus, que são muito importantes para mim, meu porto seguro. Sou muito feliz por ter voce^s. Muito obrigada por todos os momentos em que estamos juntos, pois é sempre uma alegria.

Esta conquista também é de vocês. Obrigada por acreditarem em mim! Amo vocês. 
Ao meu orientador Prof. Dr. Arthur Belém Novaes Júnior, por transmitir seus conhecimentos e experiências profissionais. Expresso meu sincero agradecimento e meu profundo respeito.

Agradeço pelas palavras, tempo e atenção dedicados a mim e pela orientação na minha formação profissional.

À minha coorientadora Profa. Dra. Léa Assed Bezerra da Silva, por ter me recebido e acolhido na Odontopediatria. Agradeço pela sua dedicação, apoio e atenção, desde o início, que foram fundamentais para a realização deste trabalho. Obrigada por acreditar na minha capacidade e pelo incentivo constante ao aprendizado e à Pesquisa.

Agradeço pelas vezes que dedicou o seu tempo me ajudando e me orientando diretamente durante os experimentos. Obrigada por me incentivar e me ajudar a crescer sempre. Obrigada por seus ensinamentos, conselhos e orientações.

Ao Prof. Dr. Paulo Nelson Filho, meu supervisor no estágio do PAE e muito presente nesses quatro anos de doutorado. Grande exemplo de mestre, com toda sua disciplina e sabedoria. Obrigada por não medir esforços para me ajudar em tudo que precisei. 
À Faculdade de Odontologia de Ribeirão Preto da Universidade de São Paulo, na pessoa da atual Diretora Profa.Dra. Léa Assed Bezerra da Silva e do Vice-Diretor Prof. Dr. Arthur Belém Novaes Júnior.

À Coordenação do Curso de Pós-Graduação em Odontopediatria da Faculdade de Odontologia de Ribeirão Preto da Universidade de São Paulo, na pessoa da Coordenadora Profa. Dra. Raquel Assed Bezerra Segato e da ViceCoordenadora Profa. Dra. Léa Assed Bezerra da Silva.

Aos Professores do Departamento de Clínica Infantil:

Profa. Dra. Aldevina Campos de Freitas, Profa. Dra. Alexandra Mussolino de Queiroz, Profa. Dra. Andiara De Rossi Daldegan, Prof. Dr. Fabrîcio Kitazono de Carvalho, Profa. Dra. Kranya Victória Díaz Serrano, Profa. Dra. Léa Assed Bezerra da Silva, Prof. Dr. Paulo Nelson Filho, Profa. Dra. Raquel Assed Bezerra Segato, Profa. Dra. Maria Cristina Borsatto, Profa. Dra. Maria da Conceição Pereira Saraiva, Profa. Dra. Mírian Aiko Nakane Matsumoto, Profa. Dra. Maria Bernadete Sasso Stuani, Prof. Dr. José Tarcisio Lima Ferreira, Prof. Dr. Adilson Thomazinho, Prof. Dr. Fábio Lourenço Romano, pela agradável convive ncia, pelas conversas atenciosas e pelos valiosos ensinamentos. Por oferecerem suporte para a adequada realização das atividades clínicas e científicas durante o período do Doutorado.

À amiga Marília Pacífico Lucisano Politi, um anjo que Deus colocou em minha vida! O meu doutorado se tornou mais fácil por ter você presente sempre e porque muitas vezes você foi a força que precisei. Obrigada pela amizade sincera. Minha companheira de todas as horas, obrigada pela ajuda na execução desse trabalho. Obrigada por dividir suas experiências comigo e por estar sempre disposta a ajudar. Você foi fundamental nessa fase da minha vida. 
Ao Dr. Francisco Wanderley Garcia de Paula e Silva, agradeço pela paciência, ensinamento, humildade e respeito que sempre dispensou a mim, suporte fundamental para o meu crescimento pessoal e profissional.

Aos professores da banca examinadora, pela atenção dispensada na leitura desta tese.

Aos funcionários do Departamento de Clínica Infantil da Faculdade de Odontologia de Ribeirão Preto:

Marco Antonio dos Santos, obrigada pela convivência, pelas conversas e pelo carinho desde o início. Obrigada por sua participação direta na fase laboratorial deste trabalho e por ter preparado as lâminas histológicas com tanto cuidado.

Nilza Letícia Magalhães, obrigada pela ajuda na execução de todas as metodologias realizadas neste trabalho. Obrigada por estar sempre disposta a ajudar e tornando a execução dos experimentos mais agradável com sua alegria.

Fátima Aparecida Jacinto, pela companhia no laboratório, pelas ajudas oferecidas e pelo apoio de sempre.

Filomena Leli Placciti, obrigada pela alegre convivência, pela forma simpática e carinhosa que me recebe diariamente.

Matheus Morelli Zanela, obrigada pela paciência, atenção e disponibilidade. Agradeço pelo convívio agradável e pelo carinho.

Micheli Cristina Leite Rovanholo, agradeço pela generosidade que sempre teve em esclarecer dúvidas relacionadas à Pós-Graduação, sempre atenciosa e paciente. Agradeço pelo convívio harmo nico, palavras de amizade e incentivo e respeito mútuo. Muito obrigada pela dedicação e apoio durante todo o curso. Mi, obrigada pela amizade e por me ajudar sempre.

Aos funcionários da Clínica I da Faculdade de Odontologia de Ribeirão Preto da Universidade de São Paulo, José Aparecido Neves do Nascimento, Vera do Nascimento Scandelai e Karina Dadalt Quaglio, e aos funcionários da Clínica de Pacientes Especiais, Benedita Viana Rodrigues e Fátima Aparecida Rizoli. Agradeço pela forma amiga, simpática e alegre com que sempre me acolheram. 
Às funcionárias da Seção de Pós-Graduação da Faculdade de Odontologia de Ribeirão Preto da Universidade de São Paulo, Isabel Cristina Galino Sola, Regiane Cristina Moi Sacilloto e Mary Possani, pela atenção, pelo carinho e por estarem sempre à disposição.

Aos funcionários do Biotério Aldo Dias Feiteiro Junior, Edson Campos Rodrigues dos Santos e Raphael Martini Vicente, pela gentileza e simpatia com que me receberam. Ao veterinário Fabio Rodrigues da Motta meus sinceros agradecimentos pelo apoio durante o desenvolvimento da parte experimental. Obrigada por terem sido tão prestativos e atenciosos e pelo cuidado no tratamento dos animais.

Às amigas queridas da minha turma do Doutorado, por compartilharem momentos maravilhosos, por dividirem experiências e dificuldades, pelo companheirismo e amizade. Agradeço especialmente à minha amiga Késsia Suênia Fidelis de Mesquita Guimarães. Obrigada por sua amizade verdadeira, pelo seu carinho, por me incentivar e ajudar sempre. Obrigada pelos conselhos, pelas conversas e risadas.

Aos alunos do Programa de Pós-Graduação em Odontopediatria pela agradável convivência, pelas conversas divertidas e pelos momentos compartilhados.

Às amigas Sofia Sampaio, Gabriela Flores, Claudia Carpio, Talita Prates, pelo convívio e amizade verdadeira, e pela troca de experiências culturais, pessoais e profissionais. Sinto muita saudade de todas.

Ao Diego Jesus Brandariz Pimentel, meu companheiro para todas as horas. Obrigada por fazer minha vida mais feliz e completa. Te quiero mucho!

À FAPESP (Fundação de Amparo à Pesquisa do Estado de São Paulo), pelo auxílio financeiro e pela bolsa concedida. 
A todos que contribuíram direta ou indiretamente para a concretização deste trabalho. Muito obrigada! 


\section{SuMÁRIO}

RESUMO
ABSTRACT
INTRODUÇÃO
PROPOSIÇÃO
MATERIAL E MÉTODOS
RESULTADOS
DISCUSSÃO
CONCLUSÃO
REFERÊNCIAS
ANEXO.
APÊNDICE





\section{RESUMO}

Hidalgo, LRC. Terapia fotodinâmica antimicrobiana (aPDT) no tratamento de lesões periapicais induzidas experimentalmente, em dentes de cães. [Tese]. Ribeirão Preto: Faculdade de Odontologia de Ribeirão Preto da Universidade de São Paulo; 2016.

Proposição: Avaliar in vivo o efeito da Terapia Fotodinâmica Antimicrobiana (aPDT), após tratamento endodôntico em sessão única, em dentes de cães com lesão periapical, em comparação ao tratamento em duas sessões com o uso de curativo de demora à base de hidróxido de cálcio. Material e Métodos: Após a indução experimental da lesão periapical e instrumentação dos canais radiculares, 48 dentes foram distribuídos nos seguintes grupos: I e III - Uso de curativo de demora com pasta à base de hidróxido de cálcio (Calen ${ }^{\circledR}$ ); e II e IV -Tratamento em uma única sessão com utilização da aPDT. Os canais radiculares foram obturados e decorridos os períodos experimentais de 120 dias (Grupos I e II) e 180 dias (Grupos III e IV), os animais foram submetidos à eutanásia. Após processamento histotécnico, análise microscópica descritiva/semi-quantitativa, avaliação morfométrica do tamanho da lesão periapical em microscopia de fluorescência e análise radiográfica foram realizadas. Foram utilizados os testes de Kruskal Wallis e exato de Fisher $(a=0,05)$. Resultados: Na análise microscópica descritiva, os grupos I e III apresentaram áreas cementárias reparadas, com numerosos feixes colágenos no ligamento periodontal e presença suave de células inflamatórias. Nos grupos II e IV as áreas de reabsorção cementária não estavam reparadas, com reduzida presença de células e fibras e presença de células inflamatórias. Na análise semi-quantitativa do selamento biológico apical houve diferença significante $(p<0,0001)$ entre os grupos I e II; e entre os grupos III e IV ( $p<0,0001)$. A análise em microscopia de fluorescência evidenciou diferença significante entre os grupos, após 120 dias $(p=0,0004)$ e após 180 dias $(p=0,0081)$, sendo que os grupos I e III apresentaram lesões periapicais menores. A porcentagem de redução radiográfica das lesões evidenciou diferença significante entre os grupos $(p<0,05)$, com maior porcentagem de redução para os grupos I e III. Com relação à 
análise imunohistoquímica, nos grupos I, II e IV, as marcações para RANK, RANKL e OPG indicaram sinalização pró-reabsortiva, embora a marcação para RANKL no grupo I tenha sido pouco intensa. Já no grupo III, as marcações evidenciaram ocorrência de neoformação óssea. Conclusão: 0 tratamento em duas sessões com o uso de curativo de demora à base de hidróxido de cálcio promoveu maior redução no tamanho das lesões periapicais e estágio mais avançado de reparo, evidenciado pelos melhores resultados histopatológicos, imunohistoquímicos e radiográficos, em comparação ao tratamento em uma única sessão com utilização do protocolo de aPDT avaliado.

Palavras-chaves: Lesão periapical; Terapia fotodinâmica antimicrobiana; Hidróxido de cálcio. 


\section{ABSTRACT}

\section{Hidalgo, LRC. Antimicrobial Photodynamic Therapy in the Treatment of Apical}

Periodontitis induced experimentally in dogs' teeth. [Thesis]. Ribeirão Preto: School of Dentistry of Ribeirao Preto at University of Sao Paulo; 2016.

Aims: To evaluate one-session endodontic treatment with aPDT and two-session treatment with calcium-hydroxide $(\mathrm{CH})$-based dressing in dog's teeth with apical periodontitis. Methods: After experimental induction of apical periodontitis, 48 teeth were randomly assigned to the following groups: Group I (one-session treatment with aPDT - 120 days); Group II (one-session treatment with aPDT - 180 days); Group III (two-session treatment with $\mathrm{CH}$-based dressing -120 days) and Group IV (two-session treatment with $\mathrm{CH}$-based dressing -180 days). The animals were euthanized after 120 and 180 days. After histotechnical processing, microscopic and radiographic analyses were performed. Data were analyzed by Kruskal-Wallis and Fisher's exact tests $(a=0.05)$. Results: In the microscopical analysis, Groups I and III presented repaired cemental areas, with various colagen bundles in the periodontal ligament and mild presence of inflamatory cells. In the groups III and IV the present resorbed cemental areas were not repired, with reduced number of cells and fibers and the presence of inflamatory cells. The semi-quantitative analysis of the apical clousure, there was a significant difference $(p<0.0001)$ between groups I and II; and between groups III and IV $(p<0.0001)$. In the fluorescence microscopy analysis, there was a significant difference between groups, aftter 120 days $(p=0.0004)$ and after 180 days $(p=0.0081)$. The groups I and III presented smaller periapical lesions. The percentage of radiographic reduction of lesions demonstrated a significant difference between groups $(p<0.05)$ with a higher reducton in group I and II. Regarding the immunohistochemistry analysis, in the groups I, II and IV, RANK, RANKL and OPG staining indicated pro-resorption signaling; although the RANKL immunostaining in the group I were not intense. In the group III, the immunostaining demonstrated the occurrence of bone neoformation. Conclusion: Two-session treatment with $\mathrm{CH}$ based promoted more reduction in the periapical lesion size and more repair advanced stage, 
highlighting better histopathological, immunostaining and radiographic results in comparison with one-session treatment with aPDT protocol used.

Key words: Apical periodontitis; Antimicrobial Photodynamic Therapy; Calcium Hydroxide 


\section{Introdução}





\section{INTRODUÇÃO}

Conceitualmente, a periodontite apical ou lesão periapical é caracterizada por um processo infeccioso e imunoinflamatório de longa duração nos tecidos periapicais, resultante do desequilíbrio entre o número e a virulência dos micro-organismos presentes no sistema de canais radiculares, com relação à resistência do hospedeiro (Leonardo, 2012). O tratamento endodôntico de dentes decíduos e permanentes com necrose pulpar e lesão periapical representa um desafio para a Odontologia, uma vez que o índice de sucesso é bastante inferior, em torno de $70 \%$, quanto comparado ao tratamento de dentes com necrose sem lesão periapical, os quais apresentam sucesso de 95\% (Sjögren et al., 1997; Ferreira, 2011).

O controle bacteriológico específico do sistema de canais radiculares, previamente à obturação é crítico para o sucesso da terapia endodôntica (Sjögren et al., 1997). A infecção em dentes decíduos e permanentes com necrose pulpar e lesão periapical é de natureza polimicrobiana, composta por uma microbiota mista e complexa, com predominância de micro-organismos anaeróbios, particularmente os Gram-negativos (Assed et al., 1996).

Os micro-organismos Gram-negativos, além de possuírem diferentes fatores virulência e gerarem produtos e subprodutos tóxicos aos tecidos apicais e periapicais, contêm a endotoxina em sua parede celular. Esse conhecimento é particularmente importante, uma vez que a endotoxina, também conhecida como LPS em função de sua natureza lipopolissacarídica, é liberada durante a multiplicação ou morte bacteriana. O LPS estimula a liberação de um grande número de citocinas próinflamatórias, levando à reação inflamatória e reabsorção óssea periapical (Silva et al., 2008; Haimovich et al., 2010).

A predominância de bactérias anaeróbias Gram-negativas, a grande concentração de endotoxinas bacterianas e suas implicações na região apical e periapical determinam o aparecimento de erosões cementárias que constituem verdadeiras crateras, onde se alojam os micro-organismos protegidos pelo biofilme bacteriano (Leonardo et al., 2002; Rocha et al., 2008), justificando o fracasso da terapia endodôntica. 
Para a eliminação da infecção é necessária a destruição das bactérias e seus produtos localizados não apenas na luz do canal radicular principal, mas também nas lacunas do cemento, nas crateras apicais, em todo o sistema de canais radiculares e nas áreas externas da superfície radicular (Shovelton, 1964; Leonardo, 2005; Tanomaru et al., 2008), que são áreas inacessíveis ao preparo biomecânico (Leonardo et al., 2007; Rocha et al., 2008).

A literatura é consistente ao demonstrar que o uso de um curativo de demora antibacteriano entre sessões, durante o tratamento endodôntico de dentes com lesão periapical, oferece taxas de sucesso mais elevadas em comparação ao tratamento em uma única sessão e é necessário para reduzir a contaminação microbiana e proporcionar o reparo periapical (Sathorn et al., 2009; Vera et al., 2012; Silva et al. 2014; Borsatto et al., 2016).

Desta forma, embora o preparo biomecânico do canal radicular seja a principal forma de combate à infecção endodôntica, nos casos de dentes com lesão periapical ainda é necessário o emprego da medicação intracanal entre sessões. O hidróxido de cálcio tem sido amplamente utilizado com essa finalidade devido às suas inúmeras propriedades benéficas. Dentre essas propriedades destaca-se a ação antimicrobiana (da Silva et al., 1997; Faria et al., 2005; Desai e Chandler, 2009; Mohammadi e Dummer, 2011; Saatchi et al., 2014), capacidade de estimular a mineralização, ativação da fosfatase alcalina e síntese de colágeno (Schröder, 1985), redução do exsudato nos tecidos periapicais (Allard et al., 1987) e capacidade de promover a hidrólise da endotoxina bacteriana (Nelson-Filho et al., 2002; Silva et al., 2002; Oliveira et al., 2005; Desai e Chandler, 2009). No entanto, para que o hidróxido de cálcio apresente ação antimicrobiana, é necessário a sua permanência por períodos de 15 a 30 dias no interior do canal radicular, pois sua ação ocorre por meio da liberação de íons hidroxila, originados de sua dissociação, que tornam o meio alcalino (Montagner et al., 2007).

Atualmente, esforços têm sido direcionados para buscar alternativas que sejam incorporadas ao tratamento endodôntico em única sessão, com a finalidade de se atingir um nível de sucesso equiparável ao obtido com o uso do curativo de demora com hidróxido de cálcio. Uma dessas alternativas é a Terapia Fotodinâmica Antimicrobiana (aPDT) que, recentemente, foi introduzida na Endodontia e tem sido 
considerada uma estratégia promissora (Silva et al., 2012; Gursoy et al., 2013; Chrepa et al., 2014; Trindade et al., 2015).

A aPDT pode ser definida como a erradicação de células-alvo por meio da combinação de um fotossensibilizador (corante) não tóxico e uma fonte de luz (laser) com comprimento de onda apropriado (Dougherty et al., 1998; Hamblin e Hasant, 2004; Oliveira et al., 2007). O fotossensibilizador ativado reage com o oxigênio molecular e produz oxigênio altamente reativo, com indução da morte dos microorganismos (Wainwright, 1998).

Os fotossensibilizadores possuem carga catiônica, podendo se ligar rapidamente e penetrar nas células bacterianas, apresentando um alto grau de seletividade aos micro-organismos, em relação às células do hospedeiro (Maisch et al., 2005). Assim, a utilização do laser de baixa intensidade permite diferenciar os tecidos do hospedeiro dos micro-organismos, pela captação dos fotossensibilizadores, os quais se unem aos micro-organismos alvo. Assim, apenas as células microbianas que captaram o fotossensibilizador, após aplicação do laser, são afetados pelo tratamento (Vahabi et al., 2011).

Há diferentes famílias de fotossensibilizadores, os quais podem ser classificados de acordo com o comprimento de onda capaz de realizar sua ativação. Os fotossensibilizadores ativados com 400-500nm de comprimento de onda apresentam pouca penetração nos tecidos (Profio e Doiron 1987). Por outro lado, os fotossensibilizadores da família das fenotiazinas, os quais são fotoativados pela luz com comprimento de onda que varia de $620-700 \mathrm{~nm}$, parecem ser os mais indicados para o tratamento de infecções periodontais e endodônticas, por apresentarem um maior poder de penetração (Komerik et al., 2002; Qin et al., 2008; De Almeida et al., 2008; Souza et al., 2010). Estudos desenvolvidos em modelo animal e em humanos com aPDT têm demonstrado que esta terapia reduz o número de micro-organismos (Komerik et al., 2003; Komerik et al., 2006; Hayek et al., 2005; Novaes et al., 2012), e seu uso em diversas condições infecciosas pode ser preconizado (Komerik et al., 2000; Spikes e Jori, 1987; Malik et al., 1990).

A eficácia antimicrobiana da aPDT na terapia endodôntica tem sido avaliada em diversos estudos in vitro, ex vivo, in vivo (Soukos et al., 2006; Foschi et al., 2007; Fimple et al., 2008; Garcez et al., 2008; Garcez et al.,2010; Ng et al., 2011; Silva et 
al., 2012; Yildirim et al., 2013; Xhevdet et al., 2014; da Frota et al., 2015; Borsatto et al., 2016) e, inclusive, em recentes revisões da literatura (Chrepa et al., 2014; Trindade et al., 2015). Embora os resultados sejam satisfatórios no combate à infecção endodôntica, ainda não há evidências científicas suficientes para indicar com segurança o uso da aPDT em substituição às técnicas convencionais de tratamento.

$O$ efeito e a extensão dos danos teciduais da aPDT aos tecidos alvos dependem de diversos fatores como: tipo, dose, tempo de aplicação e localização dos fotossensibilizadores; disponibilidade de oxigênio; e parâmetros relacionados à fonte de luz, incluindo o comprimento de onda $(\mathrm{nm})$, a densidade de potência $\left(\mathrm{mW} / \mathrm{cm}^{2}\right)$ e a fluência de energia $\left(\mathrm{J} / \mathrm{cm}^{2}\right)$ (Chrepa et al., 2014). Dessa forma, muitas variáveis podem influenciar o resultado desta terapia. Pesquisas recentes sugerem a necessidade de estudos adicionais para se otimizar e padronizar o protocolo da aPDT para ser utilizado clinicamente (Silva et al., 2012; Chrepa et al., 2014; Trindade et al., 2015), promovendo efeito antimicrobiano, porém preservando a vitalidade e funcionalidade dos tecidos e das células do organismo.

Para a ativação do fotossensibilizador, os lasers têm sido a fonte de luz mais indicada para a aPDT (Bouillaguet et al., 2010; Gursoy et al., 2013). Especificamente para Endodontia, sugere-se o uso de fibras ópticas intracanal para aumentar a sua eficácia (Garcez et al., 2010). A Helbo (Bredent medical, Senden, Germany) desenvolveu um sistema específico para o uso da aPDT na Endodontia, que permite uma exposição tridimensional à luz em toda a extensão do canal radicular por meio de uma ponta de fibra óptica flexível. Adicionalmente, o fotossensibilizador é apresentado em aplicador plástico com cânula de uso único, que facilita a aplicação do corante no interior do canal radicular (http://www.helbo.de/en/dentist-information/the-therapysystem.html). Até o momento, não há estudos in vivo publicados na literatura avaliando este sistema específico para Endodontia.

Assim, a aPDT como modalidade terapêutica vem sendo cada vez mais estudada na Odontologia e, especificamente em Endodontia (Seal et al., 2002, Foschi et al., 2007; Fimple et al., 2008; Fonseca et al, 2008, Garcez et al., 2008; Garcez et al., 2010; Silva et al., 2012), evidenciando sua eficácia. Porém, é importante estabelecer parâmetros para o uso seguro da aPDT em condições clínicas, por meio de estudos in vivo, de forma a promover a eliminação dos micro-organismos sem ocasionar danos 
às células dos tecidos sadios, uma vez que a maioria dos estudos são limitados à avaliação dos efeitos antimicrobianos da aPDT. Além disso, não há ainda estudos publicados direcionados à avaliação de mediadores da osteoclastogênese, em dentes tratados endodonticamente com aPDT.

Pelo exposto, o objetivo do presente estudo foi avaliar, in vivo, o efeito do uso da aPDT utilizada para o tratamento de canais radiculares em sessão única, em dentes de cães com lesão periapical induzida experimentalmente, em comparação ao tratamento em duas sessões utilizando curativo de demora à base de hidróxido de cálcio. A hipótese testada foi de que a aPDT associada ao tratamento endodôntico em sessão única resultaria na ocorrência de processo de reparo semelhante ao proporcionado pelo uso do curativo de demora entre sessões. 

Proposição 



\section{Proposição}

Objetivo geral:

O objetivo deste estudo foi avaliar, in vivo, o efeito da aPDT no tratamento de dentes de cães com lesão periapical induzida experimentalmente.

Objetivos específicos:

- Descrever as características das regiões apical e periapical e efetuar a contagem do número de células inflamatórias, em microscopia de luz convencional.

- Mensurar a extensão da área microscópica correspondente às lesões periapicais, por microscopia de fluorescência.

- Avaliar a porcentagem de redução da extensão radiográfica das lesões perapicais.

- Identificar por imunohistoquímica marcadores da osteoclastogênese (RANK, RANKL e OPG). 



\section{Material e Métodos}





\section{Material e Métodos}

O projeto de pesquisa foi aprovado pela Comissão de Ética no Ensino e na Pesquisa em Animais da Universidade de São Paulo (Processo n 19/2012) (Anexo A) e foi realizado de acordo com as normas da International Organization for Standardization (ISO) $n^{\circ}$ 7405:2008.

\section{Animais}

Foram utilizados 6 cães provenientes de uma mesma ninhada, sem raça definida, de ambos os gêneros, com 12 meses de idade e pesando, em média, 15 quilos, adquiridos do Biotério Central da Universidade Federal de Santa Catarina.

Foram selecionados os $2^{\text {os }}$ e $3^{\text {os }}$ pré-molares superiores e os $2^{\circ s}$, $3^{\text {os }}$ e $4^{\text {os }}$ prémolares inferiores de cada cão, totalizando 48 dentes (96 canais radiculares), distribuídos em 4 grupos, conforme descrito na Tabela 1.

Os cães foram mantidos no Biotério da Faculdade de Odontologia de Ribeirão Preto da Universidade de São Paulo, com livre acesso à água e dieta padrão da Unidade, durante todo o período de experimentação.

Tabela 1. Materiais utilizados, distribuição do número de dentes (raízes) para cada grupo e períodos experimentais

\begin{tabular}{clcc}
\hline Grupo & \multicolumn{1}{c}{ Tratamento } & $\begin{array}{c}\mathbf{n}^{\circ} \text { de dentes } \\
\text { (raízes) }\end{array}$ & $\begin{array}{c}\text { Período } \\
\text { Experimental }\end{array}$ \\
\hline I & $\begin{array}{l}\text { Tratamento endodôntico em duas } \\
\text { sessões com utilização de curativo de } \\
\text { demora (Calen }{ }^{\circledR} \text { ) }\end{array}$ & $\begin{array}{c}12 \text { dentes } \\
(24 \text { raízes) }\end{array}$ & 120 dias \\
II $\quad \begin{array}{l}\text { Tratamento endodôntico em uma única } \\
\text { sessão com utilização da aPDT }\end{array}$ & $\begin{array}{c}12 \text { dentes } \\
(24 \text { raízes) }\end{array}$ & 120 dias \\
III & $\begin{array}{l}\text { Tratamento endodôntico em duas } \\
\text { sessões com utilização de curativo de } \\
\left.\text { demora (Calen }{ }^{\circledR}\right)\end{array}$ & $\begin{array}{l}12 \text { dentes } \\
(24 \text { raízes) }\end{array}$ & 180 dias \\
IV & $\begin{array}{l}\text { Tratamento endodôntico em uma única } \\
\text { sessão com utilização da aPDT }\end{array}$ & $\begin{array}{l}12 \text { dentes } \\
(24 \text { raízes) }\end{array}$ & 180 dias \\
\hline
\end{tabular}




\section{Indução das lesões periapicais}

Para a realização dos procedimentos operatórios, inicialmente os animais foram pré-anestesiados, por meio de injeção por via endovenosa de $1 \mathrm{mg} / \mathrm{kg}$ de peso de Neozine (Aventis Pharma Ltda, Souzano, SP - Brasil), 15 minutos antes do ato operatório. Em seguida, foi realizada a indução da anestesia com Zoletil ${ }^{\circledR} 50$ (Virbac do Brasil, São Paulo, SP - Brasil), na dosagem de $0,1 \mathrm{~mL} / \mathrm{kg}$ de peso, por via endovenosa, para facilitar a passagem da sonda endotraqueal, necessária para realizar a anestesia inalatória. Após a intubação com sonda endotraqueal, a manutenção da anestesia foi realizada com Isoflurano (Abbott Laborat. Do Brasil Ltda. - Rio de Janeiro - RJ), utilizando o aparelho para anestesia inalatória Takaoka KT-20 (Takaoka Ind. e Com., São Paulo, SP, Brazil). Durante todo o ato operatório, os animais foram mantidos com solução isotônica de cloreto de sódio a 0,9\% (Glicolabor Industria Farmacêutica Ltda. - Ribeirão Preto - Brasil).

Foi efetuado o exame radiográfico periapical dos dentes utilizados no estudo, com filmes periapicais Ultraspeed ${ }^{\circledR}$ - tamanho 2 (Eastman Kodak Company - Rochester - USA) e aparelho de raios-X odontológico Heliodent ${ }^{\circledR}$ (Siemens - New York - USA), com $60 \mathrm{kVp}$ e $10 \mathrm{~mA}$ e tempo de exposição de 1 segundo. As radiografias foram reveladas pelo método tempo/temperatura e arquivadas em cartelas plásticas.

Todo o instrumental utilizado nos procedimentos operatórios foi esterilizado em autoclave a $121^{\circ} \mathrm{C}$, por 20 minutos. A profilaxia dental foi realizada com o objetivo de remover cálculo e biofilme dental.

Foram induzidas lesões periapicais nos 48 dentes selecionados para o estudo, de acordo com a técnica preconizada por Leonardo et al. (1993), como descrito a seguir. A abertura coronária oclusal foi realizada nos dentes selecionados utilizando pontas diamantadas esféricas no 1015 (K.G. Sorensen - São Paulo - Brasil) montadas em caneta de alta rotação, refrigeradas a ar e água sendo, a seguir, substituídas por pontas tronco-cônicas, de extremidade inativa no 3082 (K.G. Sorensen - São Paulo Brasil). Foram realizadas duas aberturas oclusais, uma mesial e outra distal, mantendose a ponte de esmalte vestíbulo-lingual, com o objetivo de prevenir fraturas coronárias.

Foi realizada a remoção da polpa coronária com cureta e irrigação da câmara pulpar com hipoclorito de sódio a 2,5\%, seguida da exploração do canal radicular com 
lima tipo $\mathrm{K} \mathrm{n} \mathrm{n}^{\circ} 15$ (Dentsply / Maillefer - Suíça), até a parada no platô apical o qual se localiza, aproximadamente, a $2 \mathrm{~mm}$ do ápice radicular.

Após o descolamento da polpa radicular, foi efetuada sua remoção com uma lima Hedströen (Dentsply / Maillefer). Após a remoção da polpa radicular, com o objetivo de contaminação, os canais radiculares foram mantidos expostos ao meio bucal, durante 7 dias quando, então, sob nova anestesia geral, foi realizada a remoção dos resíduos da câmara pulpar com auxílio de curetas e de irrigação com água destilada. Após a secagem e colocação de uma mecha de algodão na câmara pulpar, foi efetuado o selamento coronário com cimento à base de óxido de zinco e eugenol $\left(\right.$ IRM $^{\circledR}$ - Dentsply Industria e Comercio Ltda. - Petrópolis - RJ - Brasil).

$O$ analgésico Cloridrato de Tramadol (Anangon ${ }^{\circledR}$ - Laboratórios Biosintética Ltda. - São Paulo - SP) foi utilizado, visando a diminuição da sensibilidade pósoperatória, administrado por via endovenosa (Solução injetável de $50 \mathrm{mg}$ ), na dosagem de $3 \mathrm{mg} / \mathrm{Kg}$ de peso do animal, uma vez ao dia, por 3 a 4 dias. Os animais foram observados diariamente pelo médico veterinário do canil, para verificar se estavam se alimentado normalmente.

Foram realizados controles radiográficos quinzenais, até serem observadas imagens radiolúcidas, sugestivas de lesão periapical crônica, que ocorreu aproximadamente após 45 dias do selamento provisório.

\section{Neutralização do conteúdo séptico-tóxico e preparo biomecânico dos canais radiculares}

Após constatação das imagens radiolúcidas, ou seja, de lesões periapicais crônicas experimentalmente induzidas, os dentes selecionados foram isolados com dique de borracha, sendo realizada a anti-sepsia do campo operatório com peróxido de hidrogênio a 3\%, seguida pela aplicação de digluconato de clorexidina a 2,0\%. 0 cimento provisório e a mecha de algodão da câmara pulpar foram removidos e os canais radiculares submetidos à neutralização imediata do conteúdo séptico-tóxico aplicando o princípio coroa/ápice, de acordo com Leonardo (2005), sendo empregadas limas tipo K, introduzidas no canal radicular progressivamente, com diminuição gradativa de diâmetros, acompanhadas pela irrigação/aspiração e nova inundação com solução de hipoclorito de sódio a $2,5 \%$. 
Em seguida, foi realizada a tomada radiográfica periapical, pela técnica da bissetriz, objetivando-se realizar a odontometria para a obtenção do Comprimento Real do Dente (CRD) e, consequentemente, o Comprimento Real de Trabalho (CRT), estabelecido aproximadamente $2 \mathrm{~mm}$ aquém do ápice radiográfico.

Determinada a odontometria, o forame apical foi então alargado mecanicamente com limas tipo $K$ de nos 15,20 e 25 no CRD, sendo esta última lima designada de Instrumento Apical Foraminal (IAF), utilizada para padronização do diâmetro de abertura apical dos dentes em estudo. Na mesma sessão foi realizado o preparo biomecânico, empregando instrumentos de níquel-titânio do Sistema Protaper Universal (Dentsply/Maillefer) até o CRT. Após a utilização de cada instrumento, foi realizada irrigação / aspiração / inundação dos canais radiculares com solução de hipoclorito de sódio a 2,5\%.

Terminado o preparo biomecânico, uma lima tipo K no 25 (IAF) foi novamente utilizada em todo CRD, para remoção de possíveis raspas de dentina e resíduos acumulados na região do forame apical, em decorrência do preparo biomecânico.

Após nova irrigação e aspiração, os canais radiculares foram secos com pontas de papel absorvente esterilizadas de calibre compatível com o diâmetro do último instrumento utilizado no CRT.

Os canais radiculares foram então divididos em 4 grupos experimentais. Para que todas as variáveis fossem testadas em um mesmo animal, e em diferentes quadrantes, cada hemiarco recebeu um tipo de tratamento, em sistema de rodízio. Assim, os dentes utilizados nos diferentes protocolos de tratamento não ficaram próximos uns dos outros.

\section{Curativos}

Grupo I e III: os canais radiculares desses grupos foram preenchidos com pasta à base de hidróxido de cálcio (Calen ${ }^{\circledR}$ - S.S. White Artigos Dentários Ltda. - Rio de Janeiro - RJ - Brasil), empregada com o auxílio da seringa rosqueável ML (S.S. White Artigos Dentários Ltda. - Rio de Janeiro- Brasil) e agulha longa 27G (Septoject $\mathrm{XL}$ - Septodont - França), com tope de borracha, na medida do CRT. Com a finalidade de proporcionar seu contato com a superfície apical externa, foi realizado um pequeno 
extravasamento da pasta, sendo realizadas tomadas radiográficas para a comprovação do preenchimento total dos canais radiculares e do extravasamento. Após a colocação de uma mecha de algodão esterilizada na entrada dos canais radiculares, foi realizado o selamento coronário provisório com cimento à base de ionômero de vidro (Vidrion $\mathrm{R}$ - S.S.White Art. Dent. Ltda. - Rio de Janeiro - Brasil), por 15 dias. Decorrido este período, após novo isolamento absoluto, o curativo foi removido por meio de irrigações sucessivas com solução salina esterilizada e os canais radiculares foram secos com pontas de papel absorvente. A seguir, os canais foram obturados com o cimento $\mathrm{AH}$ Plus (Dentsply, De Trey, Konstanz, Germany) e cones de guta-percha. Após o corte do excesso da obturação e a condensação vertical, as câmaras pulpares foram limpas, sendo os dentes restaurados com amálgama de prata (Velvalloy - S.S.White Art. Dent. Ltda. - Rio de Janeiro - RJ), condensado sobre uma base de cimento de ionômero de vidro (Vidrion R).

Grupo II e IV: Após o preparo biomecânico, os canais radiculares foram condicionados com o fotossensibilizador (Figura $1 \mathrm{~A}$ ) à base de fenotiazina na concentração de $10 \mathrm{mg} / \mathrm{mL}$ (Helbo Blue, BREDENT Medical, Senden, Germany), com volume de $70 \mu \mathrm{L}$, durante 1 minuto. Decorrido esse período, os canais radiculares foram irrigados com água destilada esterilizada e irradiados com um laser de diodo (Helbo Therapielaser, Helbo Photodynamic Systems Grieskirchen, Áustria) (Figura 1B) portátil, movido a bateria, com $20 \mathrm{~mW}$ de potência, comprimento de onda de $660 \mathrm{~nm}$ e irradiância de $60 \mathrm{~mW} / \mathrm{cm}^{2}$, por meio de fibra óptica flexível (Figura 1C), com diâmetro de 0,6mm (Helbo 3D Pocket Probe, Helbo Photodynamic Systems Grieskirchen, Áustria). A área do spot da fibra foi equivalente a $0,002 \mathrm{~cm}^{2}$, a potência utilizada foi de $0,06 \mathrm{~W}$ e a energia utilizada foi 3,6]. Durante a irradiação, a fibra foi colocada no interior do canal radicular, no seu comprimento total. A técnica empregada para aplicação do laser foi descrita por Anić et al. (1996), ou seja, por meio de movimento vertical do ápice para a cervical, percorrendo $2 \mathrm{~mm}$ por segundo. $O$ fotossensibilizador foi irradiado como recomendado pelo fabricante, durante 1 minuto, num modo de onda contínua. A fluência entregue ao fotossensibilizador foi de $3,3 \mathrm{~J} / \mathrm{cm}^{2}$. A seguir, após irrigação com soro fisiológico e secagem com pontas de papel absorvente esterilizadas, 
os canais radiculares foram obturados com o cimento AH Plus e restaurados, da mesma maneira descrita para o Grupo I.

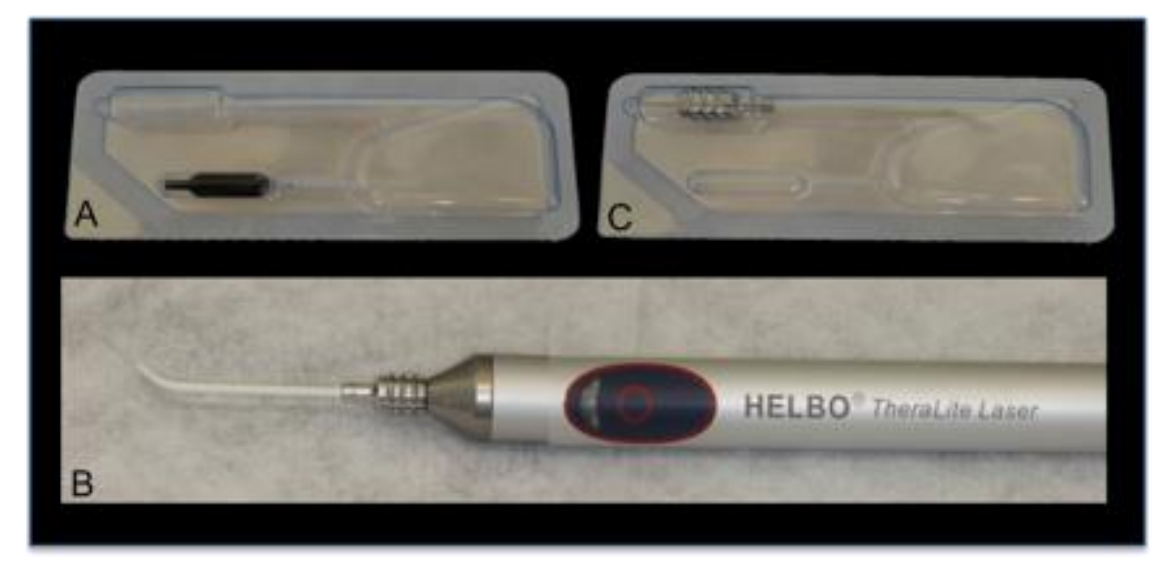

Figura 1. (A) Fotossensibilizador em embalagem individual descartável - Helbo Blue. (B) Laser Helbo Therapielaser. (C) Fibra óptica flexível descartável - Helbo 3D Pocket Probe.

Após o término dos procedimentos operatórios foi efetuado o exame radiográfico e a aplicação de analgésico (Cloridrato de Tramadol), na dosagem de $3 \mathrm{mg} / \mathrm{kg}$ de peso, por via endovenosa, a cada 12 horas, durante 2 dias. Os animais foram acompanhados durante todo o período experimental para observação de possíveis mudanças nos hábitos alimentares e desenvolvimento de processos inflamatórios ou supuração dos tecidos, dentre outras anormalidades.

Decorridos os períodos experimentais de 120 dias (Grupos I e II) e 180 dias (Grupos III e IV), as hemi-arcadas foram radiografadas, da mesma maneira descrita anteriormente, e os animais foram submetidos à eutanásia, como descrito a seguir:

1. Tranquilização com Neozine injetável, na dosagem de $1 \mathrm{mg} / \mathrm{kg}$ de peso.

2. Após 15 minutos, foi efetuada a anestesia com Tiopental (CRISTÁLIA Produtos Químicos Farmacêuticos Ltda., Itapira, Brasil) endovenoso, na dosagem de $25 \mathrm{mg} / \mathrm{kg}$ de peso, injetado lentamente.

3. Em seguida, foi efetuada a eutanásia com cloreto de potássio a $20 \%$, endovenoso, na dosagem de $100 \mathrm{mg} / \mathrm{kg}$ de peso, injetado lentamente.

As maxilas e mandíbulas foram dissecadas com auxílio de um bisturí, reduzidas em seu volume e as peças lavadas em água corrente. Para facilitar o processamento histotécnico, o material foi seccionado utilizando discos diamantados, sob constante 
refrigeração com água, sendo obtidos blocos das peças anatômicas contendo os dentes individualmente.

\section{Processamento histotécnico}

As peças foram submetidas à fixação em solução de formol tamponado a $10 \%$, por 72 horas, à temperatura ambiente. Em seguida, foram lavadas em água corrente por, aproximadamente, 4 horas. Para descalcificação das peças foi utilizada solução à base de EDTA a 10\% e pH 7,4 (EDTA Disodium Salt Dihydrate - Merck — Darmstadt, Alemanha). As peças foram mantidas nesta solução à temperatura ambiente, sobre leve agitação (8 horas/dia), trocada semanalmente, até sua completa descalcificação, a qual ocorreu após 60 dias aproximadamente.

A completa desmineralização das amostras foi avaliada por meio da penetração de uma agulha nos tecidos para verificação da sua consistência e por meio de exame radiográfico das peças.

Concluída a desmineralização, as peças foram neutralizadas em solução de sulfato de sódio a 5\% (Sulfato de Sódio Anidro - J.T.Baker - Xalostoc - México) por 24 horas, lavadas em água corrente por 24 horas, desidratadas em concentrações crescentes de álcool (70\% e 95\% por 30 minutos cada; 2 trocas de $100 \%$ por 20 minutos cada; e duas trocas de álcool $100 \%$ por 40 minutos cada) (Alcohol Etilico Absoluto - J.T. Baker - Xalostoc - México), diafanizadas em xilol (2 banhos de 20 minutos e 1 de 40 minutos) (Xylol ${ }^{\circledR}$ - Merck - Darmstadt - Alemanha) e incluídas em parafina (Histosec ${ }^{\circledR}$ Pastillen - Merck - Darmstadt - Alemanha), de acordo com a rotina histotécnica.

Os blocos contendo os dentes individualizados foram reduzidos pela microtomia a cortes seriados longitudinais com $5 \mu \mathrm{m}$ de espessura em micrótomo (Leica RM2145; Microsystems $\mathrm{GmbH}$, Wetziar) no sentido mésio-distal. Os cortes foram obtidos em toda a extensão da lesão periapical. Para cada raiz foram obtidas, em média, 14 secções. 


\section{Análise microscópica descritiva das características das regiões apical e periapical}

Para a análise descritiva das regiões apical e periapical, as lâminas foram coradas pela Hematoxilina e Eosina (HE). A análise microscópica foi realizada em microscópio Axio Imager.M1 (Carl Zeiss MicroImaging GmbH, Göttingen, Germany), acoplado a uma câmera AxioCam MRc5 camera (Carl Zeiss MicroImaging GmbH).

Foi registrada a descrição das características dos tecidos apicais e periapicais, de acordo com os seguintes parâmetros (de Rossi et al., 2008; da Silva et al., 2012):

- Cemento apical: características da superfície (regular ou irregular).

- Ligamento periodontal: extensão (normal ou aumentada), característica do infiltrado celular inflamatório, presença de edema de fibras colágenas.

- Osso a/veolar: ausência/presença de reabsorção, osteoblastos e osteoclastos.

\section{Análise microscópica semi-quantitativa}

Adicionalmente, foi realizada análise semi-quantitativa (sistema de escores), de acordo com os seguintes parâmetros:

- Espessura do ligamento periodontal: 0. Normal, 1. Suavemente aumentada, 2. Moderadamente aumentada, 3. Severamente aumentada.

- Intensidade do infiltrado inflamatório: 0. Ausente, 1. Suave, 2. Moderada, 3. Severa.

- Reabsorção de cemento e osso alveolar: 0. Ausente, 1. Presente.

- Selamento biológico após tratamento endodôntico: 0. Ausente, 1. Parcial, 2. Total.

\section{Análise em microscopia de fluorescência}

A avaliação morfométrica do tamanho da lesão periapical foi realizada nos espécimes corados com $\mathrm{HE}$, utilizando o microscópio Axio Imager.M1, em aumento de 1,25x, operando no modo fluorescente (Silva et al., 2012; Bezerra da Silva et al., 2014; Cohenca et al., 2015). Para cada espécime, a extensão (área) da lesão periapical foi 
delimitada e mensurada em $\mathrm{mm}^{2}$, usando o software Axio Vision Rel 4.8. A delimitação da lesão excluiu as áreas intactas (ligamento periodontal, cemento e osso alveolar), facilmente identificadas pela sua forte fluorescência verde, e incluiu áreas de reabsorção e infiltrado inflamatório, identificadas pela ausência de fluorescência e aparência escura.

\section{Análise Radiográfica}

De forma padronizada, foram tomadas radiografias no início do tratamento (dia 0) e 120 dias (Grupo I e II) e 180 dias (Grupo III e IV) após a obturação dos canais radiculares. Posicionadores foram empregados em todas as tomadas radiográficas. 0 aparelho de raio-x odontológico Heliodent (Siemens, Erlanger, Alemanha) foi usado com parâmetros de exposição definidos a 60kV, 10mA e 0,4 segundos, empregando películas periapicais Ultraspeed. Os filmes foram processados de acordo com o método de tempo/temperatura.

As imagens foram digitalizadas e transferidas para o programa Image J (Versão 1,28 u, Institutos Nacionais de Saúde, Washington, DC, EUA), para a mensuração das lesões periapicais e registro dos resultados.

Para cada par de imagens, as áreas radiolúcidas das lesões periapicais, quando presentes, foram demarcadas e medidas por um único examinador calibrado, cego para os grupos em análise, em $\mathrm{mm}^{2}$. A percentagem de redução do tamanho das lesões periapicais, comparando-se os períodos pré e pós-tratamento, foi calculada para cada grupo.

\section{Análise imunohistoquímica}

A análise imunohistoquímica foi realizada para identificação e localização de marcadores envolvidos na osteoclastogênese (RANK, RANKL e OPG). As reações foram realizadas utilizando o método do complexo avidina-biotina-peroxidase (método indireto). Os cortes histológicos foram desparafinizados e hidratados de forma rotineira. A recuperação antigênica foi realizada com calor, utilizando tampão citrato $(\mathrm{pH}=6,0)$ em forno de microondas (2 vezes, por 10 segundos cada). Após retorno à 
temperatura ambiente, as lâminas foram lavadas 2 vezes por 5 minutos com PBS e 1 vez com solução PBS/Triton a 0,5\% (Sigma-Aldrich Corporation, Saint Louis, EUA), também por 5 minutos. $O$ bloqueio da peroxidase endógena foi realizado com peróxido de hidrogênio a 3\%, por 20 minutos, sob proteção da luz. A seguir, as lâminas foram novamente lavadas com PBS e PBS/Triton conforme descrito anteriormente. O bloqueio das ligações inespecíficas foi realizado com solução de BSA a 1\% (albumina de soro bovino)/PBS, por 30 minutos. A seguir, as lâminas foram incubadas overnight em refrigerador com os anticorpos primários diluídos em BSA a 1\%: anti-RANK (polyclonal rabbit antibody H300 sc:9072; Santa Cruz Biotechnology Inc.; diluído 1:700), anti-RANKL (polyclonal goat antibodyn-19 sc:7628; Santa Cruz Biotechnology Inc.; diluído 1:400) e anti-OPG (polyclonal goat antibody n-20 sc:8468; Santa Cruz Biotechnology Inc.; diluído 1:700). Após retornarem à temperatura ambiente, as lâminas foram lavadas com PBS e incubadas com anticorpo secundário biotinilado (goat anti-rabbit IgG-B sc-2040 e rabbit anti-goat IgG-B sc-2774; Santa Cruz Biotechnology Inc., diluídos 1:200), por 1 hora à temperatura ambiente. Após nova lavagem, foi colocado o complexo avidina-biotina-peroxidase ( $A B C$ kit, Vectastain; Vector Laboratories Inc.), por 30 minutos. A seguir, as lâminas foram novamente lavadas com PBS e PBS/Triton e foi efetuada a revelação da reação com solução de diaminobenzidina (DAB; Sigma-Aldrich Corporation, Saint Louis, EUA) e $\mathrm{H}_{2} \mathrm{O}_{2}$ a $3 \%$ em PBS, por 1 minuto. As lâminas foram contra-coradas com Hematoxilina de Harris por 10 segundos, lavadas em água corrente, lavadas em água amoniacal por 30 segundos, lavadas em água corrente, diafanizadas, desidratadas e montadas. A identificação de marcadores da osteoclastogênese (RANK, RANKL e OPG) foi realizada em microscópio Axio Imager.M1 sob luz convencional. Os resultados foram expressos de maneira qualitativa, levando-se em consideração a presença/ausência e a localização das marcações, como descrito por da Silva et al. (2012).

\section{Análise Estatística}

Os dados obtidos foram submetidos à análise estatística empregando-se o teste de Mann-Whitney e, para dados dicotômicos, o teste exato de Fisher. Os testes foram realizados utilizando o software GraphPad Prism - version 5.0 (GraphPad Software Inc., San Diego, CA, USA). O nível de significância adotado foi de $5 \%$. 
Resultados 



\section{Resultados}

\section{Análise microscópica descritiva}

Período de 120 dias:

A análise microscópica descritiva evidenciou que, no grupo I (tratamento endodôntico em duas sessões com utilização de curativo de demora com pasta à base de hidróxido de cálcio), os espécimes apresentaram áreas cementárias reparadas, com numerosos feixes colágenos no ligamento periodontal e presença suave de células inflamatórias difusas. A espessura do ligamento periodontal era suavemente aumentada.

No grupo II (tratamento endodôntico em uma única sessão com utilização da aPDT), as áreas de reabsorção cementária não estavam reparadas em alguns casos e havia a presença de células inflamatórias, predominantemente mononucleadas, além de poucos delicados feixes de fibras colágenas. A superfície óssea encontrava-se frequentemente desnuda.

Período de 180 dias:

No grupo III (duas sessões de tratamento endodôntico com utilização de curativo de demora com pasta à base de hidróxido de cálcio), os espécimes apresentaram áreas cementárias reparadas, com numerosos feixes colágenos no ligamento periodontal e presença escassa de células inflamatórias difusas. Na maioria dos espécimes a espessura do ligamento periodontal era normal ou suavemente aumentada e mostrava um processo de reparo avançado.

No grupo IV (uma sessão de tratamento endodôntico com utilização da aPDT), as áreas de reabsorção cementária não estavam reparadas e havia leve presença de células inflamatórias, predominantemente mononucleadas e presença moderada de delicados feixes de fibras colágenas e fibroblastos jovens.

A Figura 2 apresenta as imagens representativas de cada tratamento, evidenciando os eventos histopatológicos observados. 
Figura 2. Fotomicrografias de secções microscópicas em HE representativas dos grupos avaliados.

Grupos I e III:

(A) Vista panorâmica do ápice da raiz mostrando ligamento periodontal normal, ausência de células inflamatórias e selamento biológico parcial.

(B) Região do ápice mostrando intensa formação de tecido mineralizado apical recémformado. Ligamento periodontal com presença moderada de células inflamatórias. Osso alveolar com intensa presença de osteoblastos na sua superfície.

(C) Presença de selamento biológico apical. Ligamento periodontal normal e osso alveolar mostrando fase final de reparo.

Grupos II e IV:

(D) Região do ápice radicular mostrando áreas de reabsorção não reparadas. Ligamento periodontal moderadamente aumentado, com presença moderada de células inflamatórias.

(E) Ausência de selamento biológico apical e suave presença de células inflamatórias.

(F) Intensa dissociação fibrillar destacado em uma ampliação maior.

Barras de escala $=50 \mu \mathrm{m}$. 

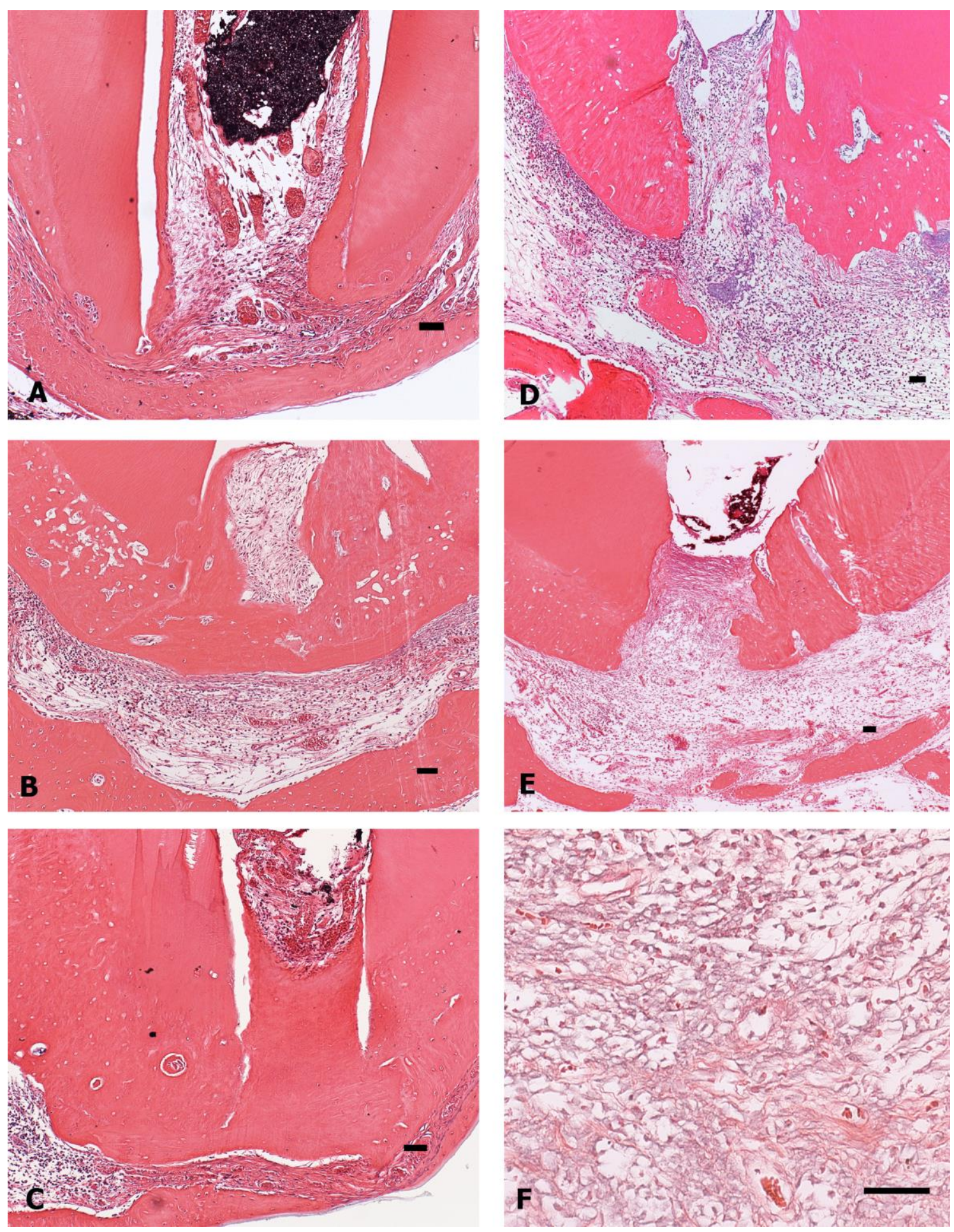



\section{Análise microscópica semi-quantitativa}

Período de 120 dias:

Os resultados obtidos na análise semi-quantitativa (escores), após 120 dias, estão apresentados nas Figuras 3 e 4. A análise estatística revelou que, com relação à espessura do ligamento periodontal, após 120 dias de tratamento, houve diferença significante entre os grupos $(p<0,0001)$ sendo que, no grupo I, o ligamento estava normal em $10 \%$ dos espécimes, suavemente aumentado em $60 \%$ e moderadamente aumentado em $30 \%$. Não houve casos de ligamento severamente aumentado nesse grupo. Por outro lado, o grupo II não apresentou espécimes (0\%) com ligamento normal, enquanto que $20 \%$ apresentaram-se com ligamento suavemente aumentado, $70 \%$ moderadamente aumentado e $10 \%$ com ligamento severamente aumentado.

Com relação à intensidade do infiltrado inflamatório, no período de 120 dias, houve diferença significante entre os grupos $(p<0,0001)$, sendo que o grupo I apresentou $50 \%$ de infiltrado ausente e $50 \%$ suave, enquanto que o grupo II apresentou $40 \%$ ausente, $40 \%$ suave, $15 \%$ moderado e $5 \%$ severo.

Com relação à presença ou ausência de reabsorção de cemento e osso alveolar, após 120 dias, houve diferença significante entre os grupos $(p=0,0015)$, sendo que $100 \%$ dos espécimes do grupo I não apresentam reabsorção, enquanto que no grupo II, em $10 \%$ havia presença de reabsorção.

Com relação à presença de selamento biológico, após 120 dias, também foi possível observar diferença significante entre os grupos $(p<0,0001)$. O grupo I apresentou $50 \%$ de selamento ausente, $17 \%$ de selamento parcial e $33 \%$ de selamento total; enquanto que o grupo II apresentou $95 \%$ de selamento ausente, $5 \%$ de selamento parcial e nenhum caso de selamento total. 

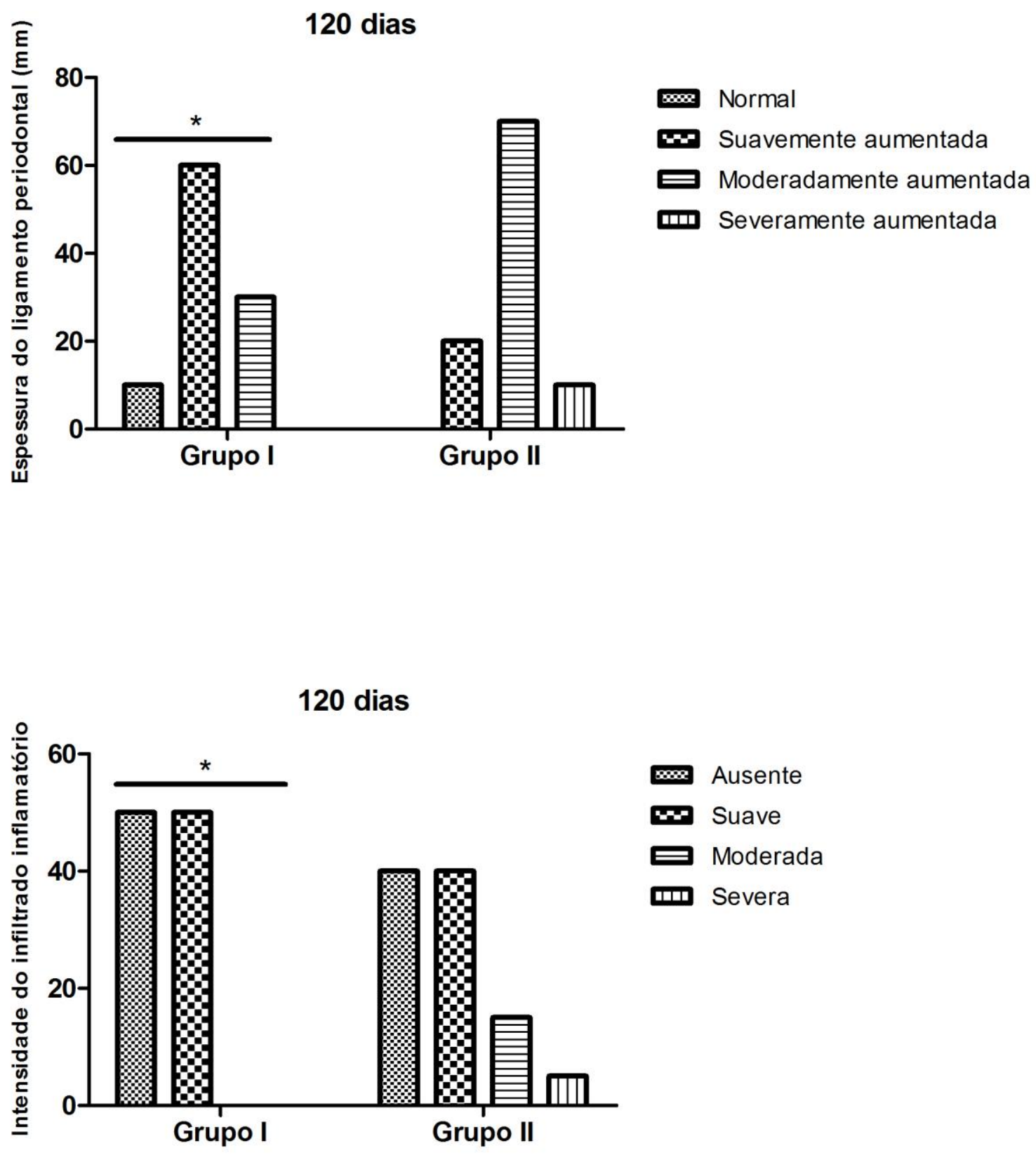

Figura 3. Gráficos dos resultados da análise semi-quantitativa (escores), após 120 dias, com relação à espessura do ligamento periodontal e intensidade do infiltrado inflamatório. * indica diferença estatisticamente significante entre os grupos $(p<0,05)$. 


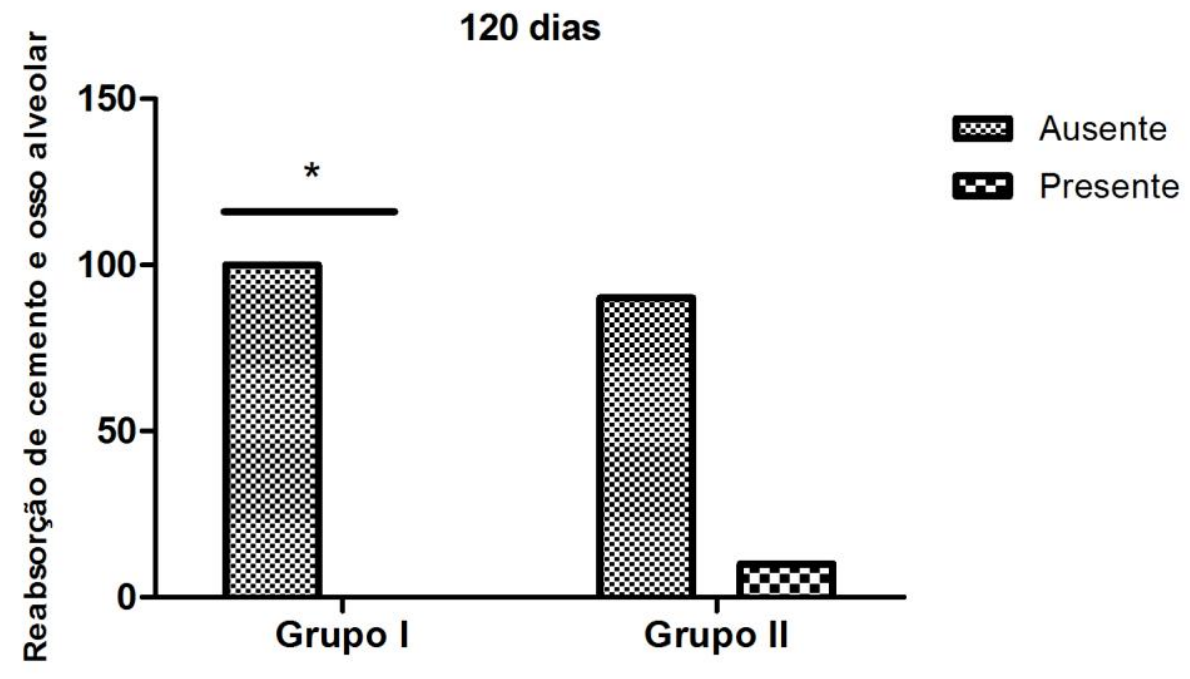

120 dias

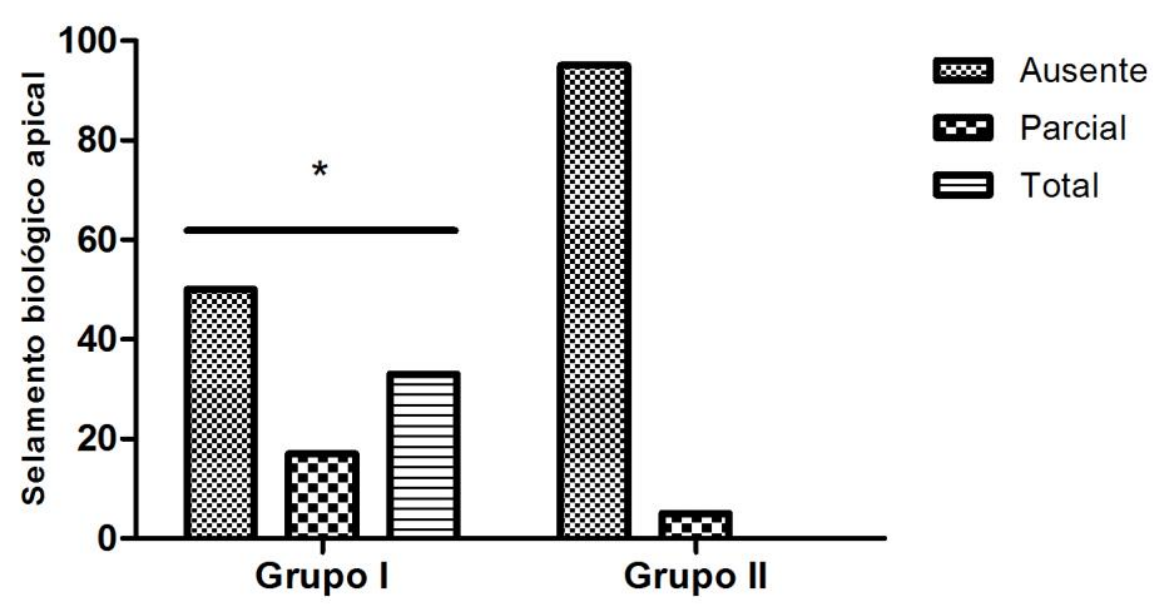

Figura 4. Gráficos dos resultados da análise semi-quantitativa (escores), após 120 dias, com relação à reabsorção do cemento e osso alveolar e presença de selamento biológico. * indica diferença estatisticamente significante entre os grupos $(p<0,05)$. 

Período de 180 dias:

Os resultados obtidos na análise semi-quantitativa (escores), após 180 dias, estão apresentados nas Figuras 5 e 6 . A análise estatística revelou que com relação à espessura do ligamento periodontal, após 180 dias de tratamento, houve diferença estatisticamente significante entre os grupos ( $p<0,0001)$, sendo que no grupo III, 0 ligamento estava normal em $35 \%$ dos espécimes, suavemente aumentado em $20 \%$, moderadamente aumentado em $20 \%$ e severamente aumentado em $25 \%$. Por outro lado, o grupo IV apresentou 5\% dos espécimes com ligamento normal, 35\% com ligamento suavemente aumentado, 55\% moderadamente aumentado e $5 \%$ com ligamento severamente aumentado.

Com relação à intensidade do infiltrado inflamatório, no período de 180 dias, não houve diferença significante entre os grupos ( $p=0,6714)$, sendo que o grupo III apresentou $40 \%$ de infiltrado inflamatório ausente, $55 \%$ suave e $5 \%$ moderado; enquanto que o grupo IV apresentou $34 \%$ ausente, $61 \%$ suave e $5 \%$ moderado.

Com relação à presença ou ausência de reabsorção de cemento e osso alveolar, após 180 dias, houve diferença significante entre os grupos $(p=0,0015)$, sendo que $85 \%$ dos espécimes do grupo III não apresentam reabsorção, enquanto que no grupo IV, em 34\% havia presença de reabsorção.

Com relação à presença de selamento biológico apical, após 180 dias, também foi possível observar diferença entre os grupos $(p<0,0001)$. 0 grupo III apresentou $52 \%$ de selamento ausente, $29 \%$ de selamento parcial e $19 \%$ de selamento total; enquanto que o grupo IV apresentou $89 \%$ de selamento ausente, $11 \%$ de selamento parcial e nenhum caso de selamento biológico apical total. 

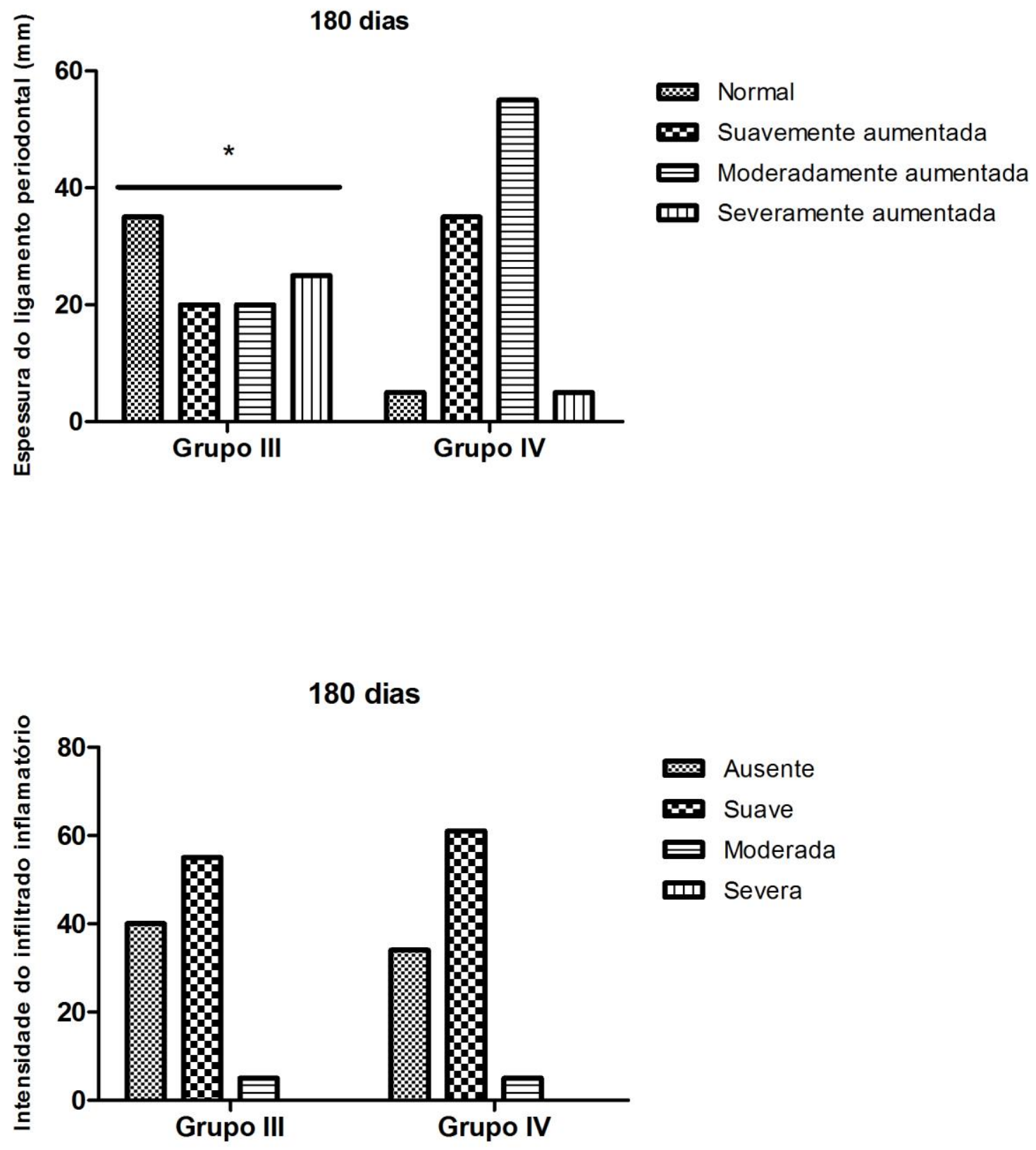

Figura 5. Gráficos dos resultados da análise semi-quantitativa (escores), após 180 dias, com relação à espessura do ligamento periodontal e intensidade do infiltrado inflamatório. * indica diferença estatisticamente significante entre os grupos $(p<0,05)$. 


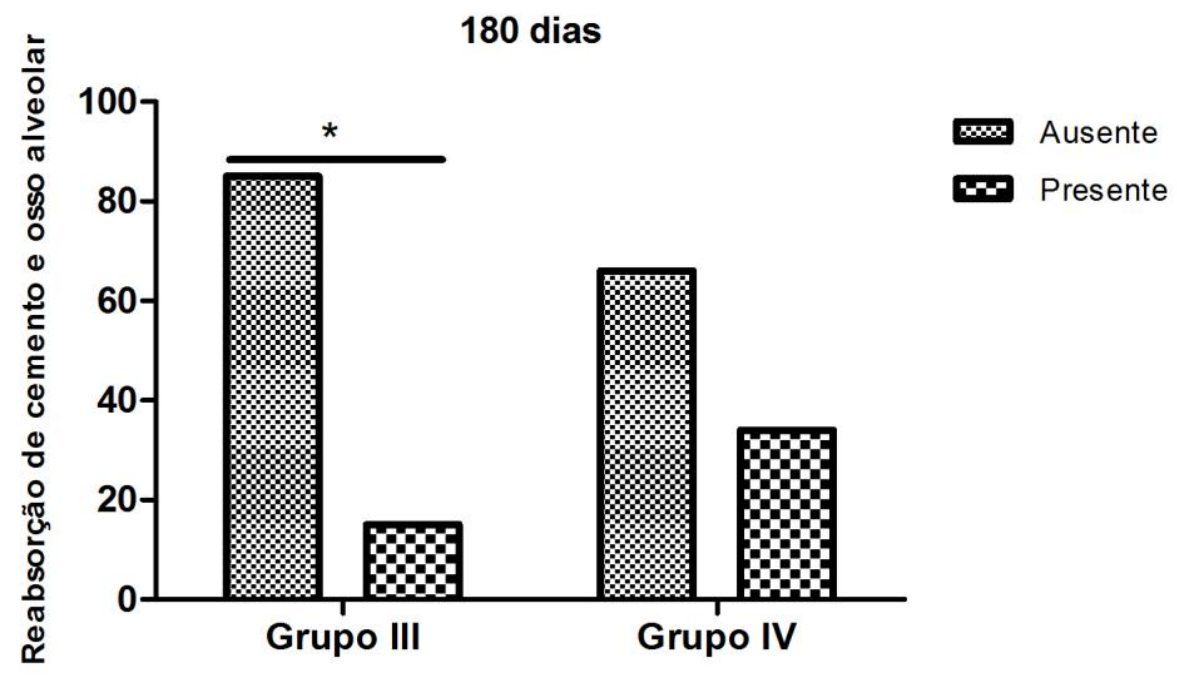

180 dias

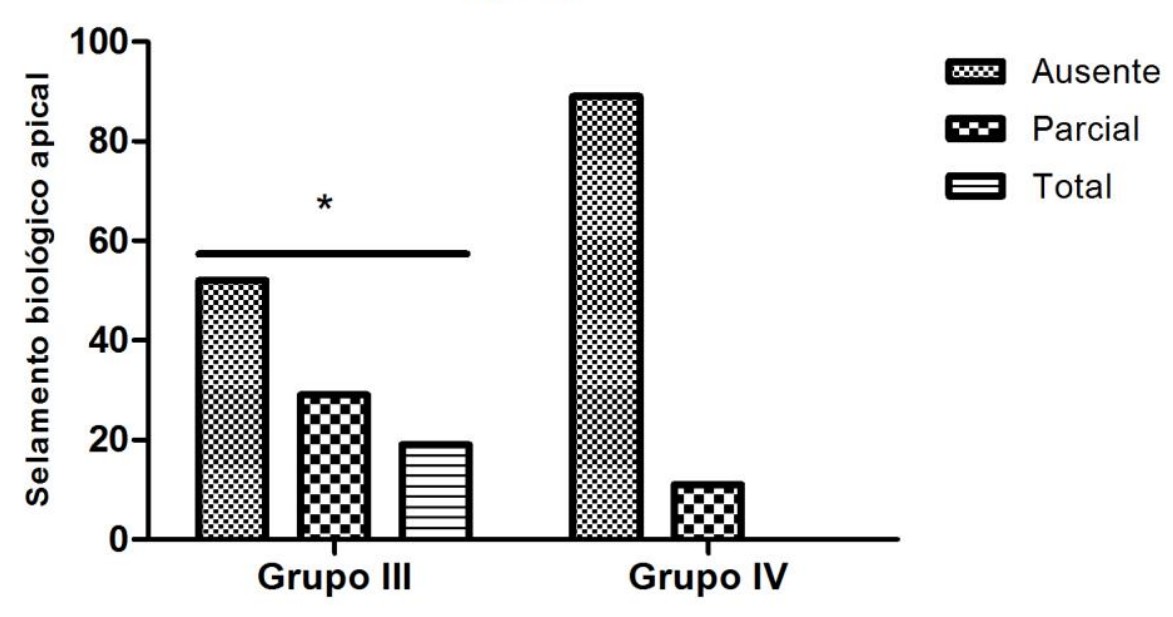

Figura 6. Gráficos dos resultados da análise semi-quantitativa (escores), após 180 dias, com relação à reabsorção do cemento e osso alveolar e presença de selamento biológico. * indica diferença estatisticamente significante entre os grupos $(p<0,05)$. 


\section{Análise em microscopia de fluorescência}

A Figura 7 ilustra a comparação da mensuração da área das lesões periapicais $\left(\mathrm{mm}^{2}\right)$, em microscopia de fluorescência, entre os grupos I e II (120 dias) e III e IV (180 dias). A análise dos dados, evidenciou diferença significante entre os grupos após 120 dias ( $p=0,0004)$ e após 180 dias $(p=0,0081)$ sendo que, para ambos os períodos de avaliação, o grupo que recebeu duas sessões de tratamento endodôntico com utilização de curativo de demora com pasta à base de hidróxido de cálcio apresentou lesões periapicais significantemente menores, em comparação ao grupo que recebeu uma sessão de tratamento endodôntico com utilização da aPDT. 


\section{0 dias}

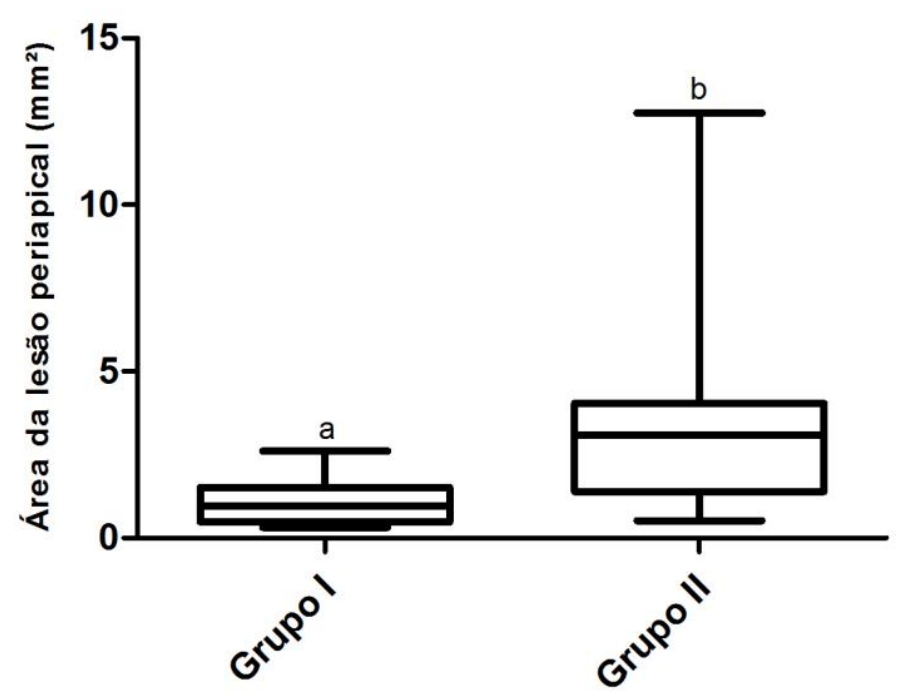

180 dias

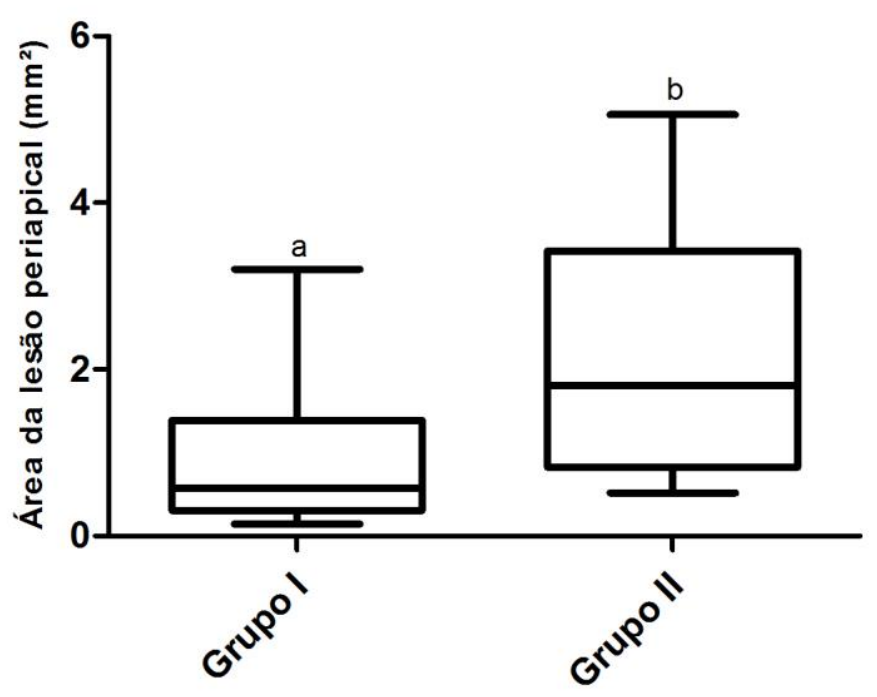

Figura 7. Box plot apresentando valor mínimo, primeiro quartil, mediana, terceiro quartil e valor máximo, após comparação da mensuração da área das lesões periapicais $\left(\mathrm{mm}^{2}\right)$, em microscopia de fluorescência, entre os dois tratamentos (tratamento endodôntico em duas sessões utilizando curativo com pasta à base de hidróxido de cálcio - I e III versus uma sessão de tratamento endodôntico com utilização da aPDT - II e IV), após 120 dias e 180 dias. Letras diferentes indicam diferença estatisticamente significante $(p<0,05)$. 


\section{Análise Radiográfica}

A comparação entre os dois tratamentos evidenciou diferença significante com relação à porcentagem de redução radiográfica das lesões periapicais, nos dois períodos avaliados: 120 dias $(p=0,0008)$ e 180 dias $(p=0,0195)$. Para ambos os períodos de avaliação, o grupo que recebeu o curativo de demora com pasta à base de hidróxido de cálcio apresentou maior porcentagem de redução das lesões periapicais $(p<0,05)$ (Figura 8$)$. 
120 dias

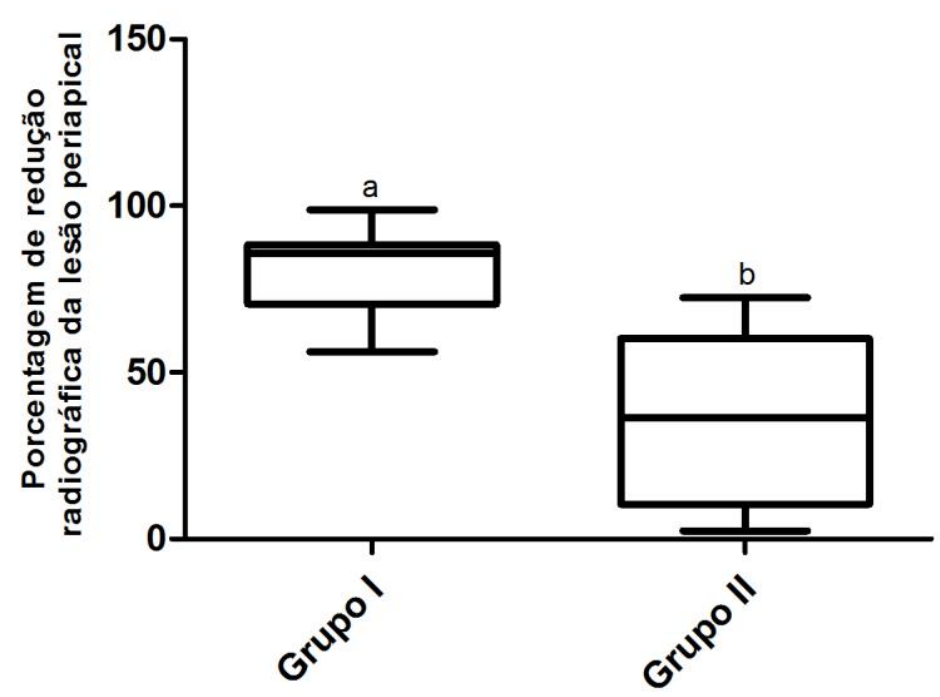

180 dias

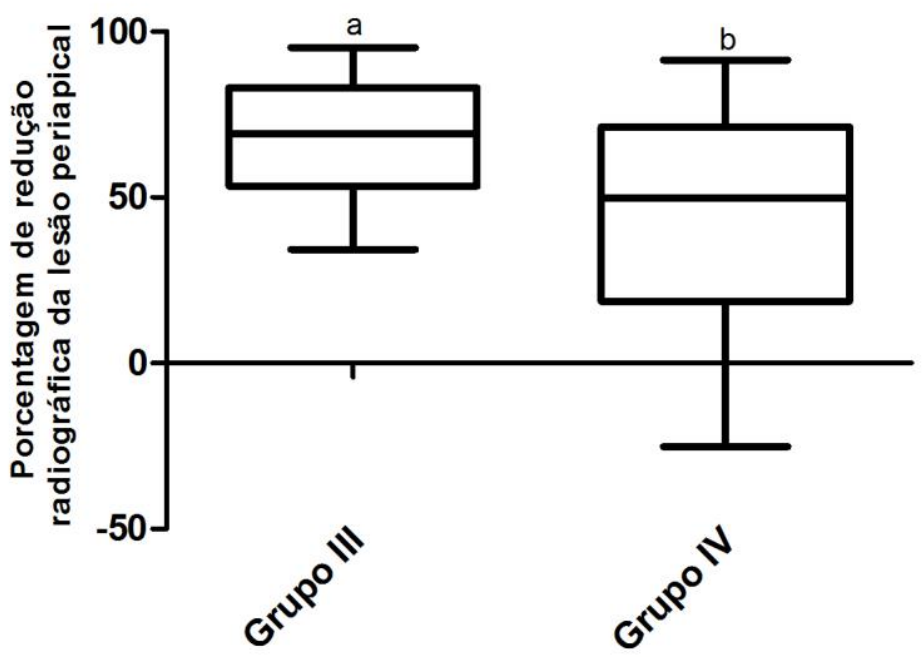

Figura 8. Box plot apresentando valor mínimo, primeiro quartil, mediana, terceiro quartil e valor máximo, após comparação da porcentagem de redução da lesão entre os dois tratamentos (tratamento endodôntico em duas sessões utilizando curativo com pasta à base de hidróxido de cálcio - I e III versus uma sessão de tratamento endodôntico com utilização da aPDT II e IV), após 120 dias e 180 dias. Letras diferentes indicam diferença estatisticamente significante $(p<0,05)$. 


\section{Análise imunohistoquímica}

Aos 120 dias, no Grupo I (duas sessões de tratamento endodôntico com utilização de curativo de demora com pasta à base de hidróxido de cálcio), a marcação para RANKL foi pouco intensa nas lacunas cementárias e na região periapical. Quando presente, localizava-se principalmente nas células polimorfonucleadas. A marcação para OPG estava presente somente em poucos osteoclastos e ausente nas lacunas cementárias. Marcação para RANK foi encontrada nos cementócitos presentes nas lacunas cementárias. Estes resultados indicam presença reduzida de sinalização próreabsorção.

No Grupo II (uma sessão de tratamento endodôntico com utilização da aPDT), foi identificada marcação positiva para RANKL nas lacunas cementárias e na lesão periapical, principalmente nas células polimorfonucleadas próximas ao forame. Marcações positivas nas lacunas cementárias e nos osteoblastos estavam presentes. Marcação muito leve para OPG estava presente nas lacunas cementárias. RANK foi pouco expresso na lesão periapical, em algumas células polimorfornucleadas e mononucleadas. Estes resultados indicam a presença de sinalização pró-reabsorção.

Aos 180 dias, no Grupo III (duas sessões de tratamento endodôntico com utilização de curativo de demora com pasta à base de hidróxido de cálcio), observouse que houve redução na expressão de RANKL nas lacunas cementárias. Os fibroblastos, cementoblastos e osteoblastos não apresentavam marcação para RANKL. A marcação para OPG estava presente principalmente nas células polimorfonucleadas e osteoblastos, sendo possível observar a linha de neoformação óssea bem delimitada, indicando um processo de remodelação óssea. Para RANK, quando haviam células polimorfonucleadas, estas estavam positivamente marcadas.

Aos 180 dias, no Grupo IV (uma sessão de tratamento endodôntico com utilização da aPDT), foram mantidas as marcações positivas para RANKL nas lacunas cementárias e na lesão periapical próxima às áreas de reabsorção. Osteoclastos presentes nas margens da lesão expressaram RANKL, indicando manutenção ou ausência do controle da reabsorção. Foi observada marcação para OPG nas lacunas cementárias e nas células mononucleadas e fibroblastos. Para RANK, as lacunas 
cementárias estavam bem marcadas e marcações positivas nos osteclastos estavam presentes, assim como em alguns macrófagos próximos à abertura foraminal.

Resumidamente, nos grupos I, II e IV, as marcações para RANK, RANKL e OPG indicaram sinalização pró-reabsortiva, embora a marcação para RANKL no grupo I tenha sido pouco intensa. Já no grupo III, as marcações evidenciaram ocorrência de neoformação óssea.

As Figuras 9 e 10 apresentam as imagens representativas da análise imunohistoquímica de cada tratamento. 
Figura 9. Fotomicrografias de cortes microscópicos representativos dos grupos I e III, submetidos à técnica de imunohistoquímica, evidenciando a presença e localização dos marcadores da osteoclastogênese RANKL $(A, B)$, OPG $(C, D)$ e RANK $(E, F)$. Barras de escala $=50 \mu \mathrm{m}$. 

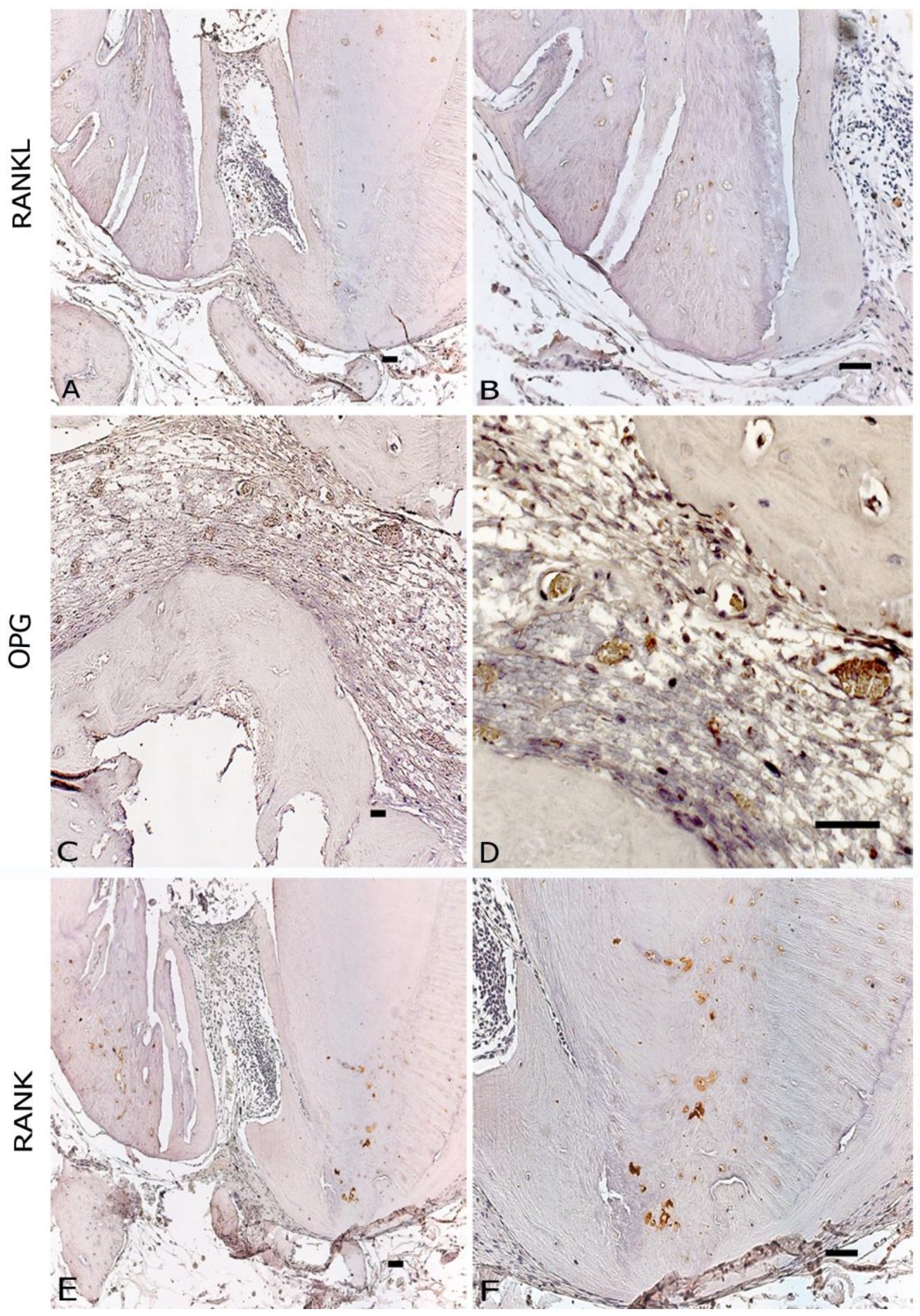
Figura 10. Fotomicrografias de cortes microscópicos representativos dos grupos II e IV, submetidos à técnica de imunohistoquímica, evidenciando a presença e localização dos marcadores da osteoclastogênese RANKL $(A, B)$, OPG $(C, D)$ e RANK $(E, F)$. Barras de escala $=50 \mu \mathrm{m}$. 

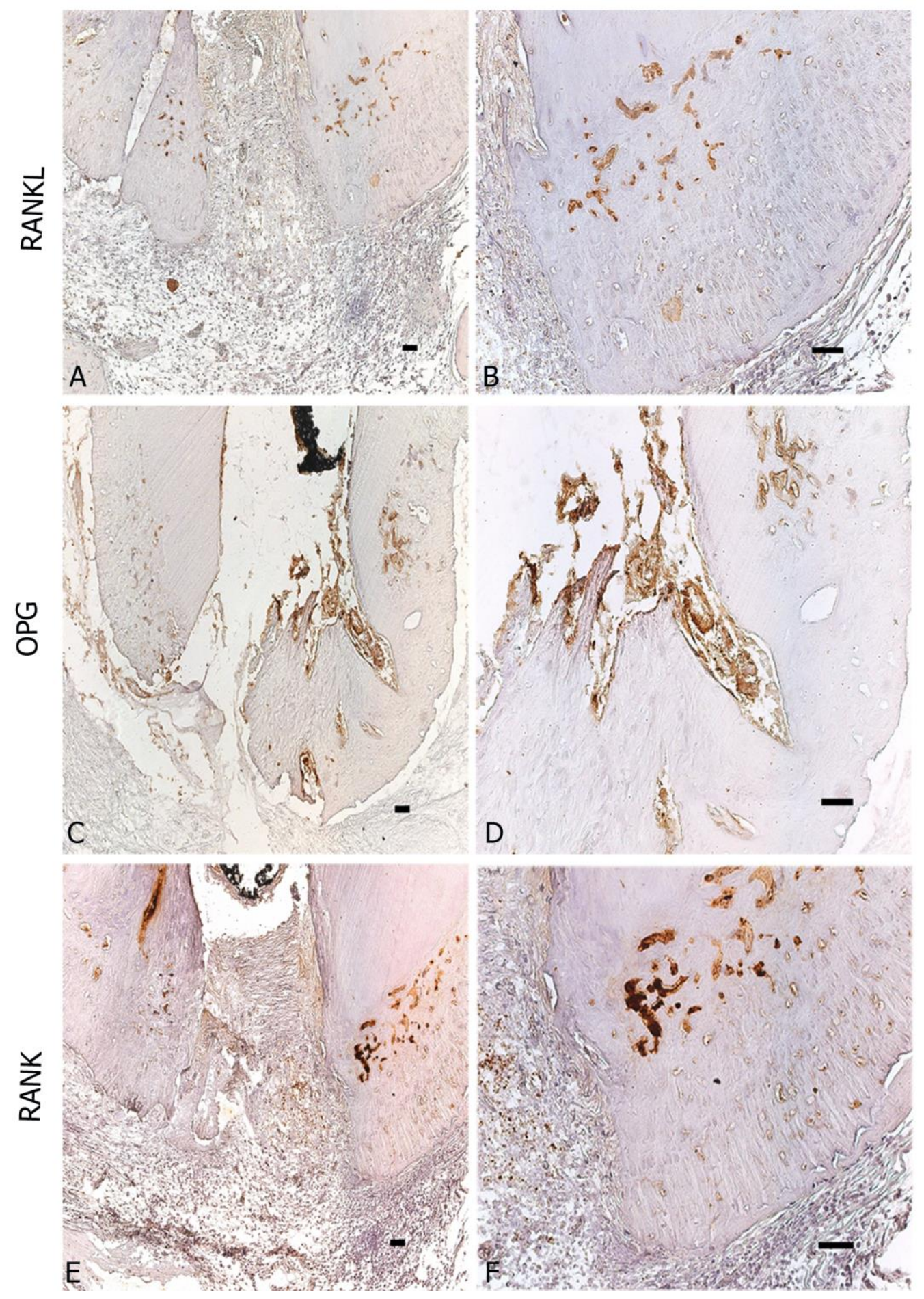

$D_{\text {iscussão }}$ 



\section{Discussão}

O presente estudo foi estruturado com o objetivo de comparar a resposta de dentes de cães com lesão periapical frente ao tratamento endodôntico em duas sessões com pasta à base de hidróxido de cálcio, em comparação a um protocolo que utiliza a aPDT em uma única sessão. Os grupos submetidos ao tratamento em duas sessões foram considerados como referência, uma vez que os mecanismos de ação do hidróxido de cálcio têm sido amplamente estudados (Silva et al., 2008; Paula-Silva et al., 2010), e que a literatura demonstra, em estudos histopatológicos, que o protocolo de tratamento empregando esse medicamento proporciona maiores taxas de sucesso e promove reparo periapical (Desai e Chandler 2009; Vera et al., 2012; Silva et al., 2014).

O mecanismo de ação do hidróxido de cálcio é bem estabelecido (Desai e Chandler, 2009). Resumidamente, quando esse material entra em contato com os tecidos, libera íons cálcio e hidroxila, os quais induzem a formação de tecido mineralizado e o efeito antimicrobiano, respectivamente. $\mathrm{O}$ seu elevado $\mathrm{pH}$, responsável pelo potencial antimicrobiano, promove uma área de necrose surperficial inicial, que é imediatamente seguida pela formação de colágeno e posterior mineralização (Manhart, 1982).

Por outro lado, a aPDT é uma terapia baseada na utilização de um fotossensibilizador que, quando ativado por luz de comprimento de onda apropriado, gera oxigênio singleto e radicais livres (Hamblin e Hasan, 2004). Estas espécies citotóxicas são altamente reativas e são conhecidas por destruir vários componentes bacterianos, tais como parede celular, proteínas e ácidos nucléicos da membrana, resultando em morte celular (Dougherty et al., 1998; Sharman et al., 1999; Hamblin e Hasan, 2004; George e Kishen, 2008).

Embora os estudos in vitro tenham demostrado elevado efeito antimicrobiano contra patógenos endodônticos utilizando a aPDT (Garcez et al., 2010; Kranz et al., 2011; $\mathrm{Ng}$ et al., 2011; Siqueira e Rôças, 2011; da Frota et al., 2015; Susila et al., 2016), apontaram a necessidade da padronização dos parâmetros para sua utilização clínica, de maneira que esta terapia promova a inativação fotodinâmica dos microorganismos, sem causar danos às células sadias. Além disso, em estudos in vivo na 
Endodontia, os resultados ainda não são consistentes para indicar a utilização da aPDT, em substituição ao tratamento convencional (Silva et al., 2012; Borsatto et al., 2016).

Em estudos prévios que avaliaram o reparo apical e periapical em períodos de até 90 dias, foi sugerido que, se um período maior fosse utilizado, possivelmente uma evolução do processo de reparo seria observada nos grupos tratados com a aPDT (Silva et al., 2012; Borsatto et al., 2016). No entanto, no presente estudo, observouse uma resposta indicativa de reparo tardio após o tratamento endodôntico empregando a aPDT, evidenciada pela leve presença de células inflamatórias, presença moderada de delicados feixes de fibras colágenas e fibroblastos jovens. Esses resultados demonstraram que o protocolo para uso endodôntico da aPDT não promoveu resposta histopatológica, imunohistoquímica e radiográfica igual ou superior à observada com o uso do curativo de demora, mesmo após períodos longos de avaliação (120 e 180 dias).

Diferentemente dos estudos que avaliaram os aspectos biológicos da aPDT em Odontologia, publicados até o momento (Silva et al., 2012; Novaes et al., 2012; Borsatto et al., 2016), ressalta-se que, no presente estudo, foi utilizado um sistema específico para o uso na Endodontia (Helbo - Bredent medical, Senden, Germany), que permite uma exposição tridimensional do laser em toda a extensão do canal radicular por meio de uma ponta de fibra óptica flexível, o que poderia favorecer a sua ação. Adicionalmente, os canais radiculares foram condicionados com o fotossensibilizador à base de fenotiazina na concentração de $10 \mathrm{mg} / \mathrm{mL}$ em um sistema próprio para o uso em canais radiculares (Helbo Blue, BREDENT medical, Senden, Germany). Os corantes fenotiazínicos, cuja estrutura fundamental é composta por um anel aromático tricíclico, são os mais utilizados e amplamente estudados para a realização da aPDT, sendo ativados pela luz no espectro de 620 a 700nm (luz vermelha) (Harris et al., 2005; Gursoy et al., 2013; Garcia et al., 2014). Esses corantes apresentam natureza hidrofílica, baixo peso molecular e carga positiva que facilitam a passagem pela parede celular das bactérias Gram-negativas (Fimple et al., 2008; Upadya e Kishen, 2010; Trindade et al., 2015), induzindo danos aos ácidos nucléicos, proteínas e lipídeos (Garcia et al., 2014). Sabe-se que esse fotossensibilizador leva à fototoxicidade de espécies Gram-positivas, que são eficientemente inativadas pela aPDT (Hamblin e Hasan, 2004). 
No presente estudo, mesmo tendo sido utilizado um sistema de fornecimento de luz e fotossensibilizador, específicos para uso em Endodontia, os resultados se assemelharam aos obtidos em estudos anteriores já publicados pelo nosso grupo de pesquisa (Silva et al., 2012; Borsatto et al., 2016), ou seja, o uso da aPDT em sessão única apresentou resultados histopatológicos inferiores ao tratamento endodôntico em duas sessões, com relação ao reparo apical e periapical em dentes portadores de necrose pulpar e lesão periapical.

Por meio da análise imunohistoquímica, no presente estudo, observou-se que, no grupo submetido ao tratamento endodôntico em duas sessões utilizando curativo à base de hidróxido de cálcio, houve redução na expressão de RANKL nas lacunas cementárias, comparando-se os dois períodos avaliados (120 e 180 dias). Além disso, após 180 dias, os fibroblastos, cementoblastos e osteoblastos não apresentaram marcação para RANKL e marcações positivas para OPG estavam presentes principalmente nas células polimorfonucleadas e osteoblastos, sendo possível observar a linha de neoformação óssea bem delimitada, indicando um processo de reparo ósseo. No entanto, no grupo tratado em única uma sessão com utilização da aPDT, foi observado similaridade nos dois períodos de avaliação. As marcações positivas para RANKL nas lacunas cementárias e na lesão periapical indicaram manutenção ou ausência do controle da reabsorção. Fundamentando parcialmente estes resultados, um estudo recente (De Rossi et al., 2016) demonstrou que os cementócitos expressam RANKL em resposta à infecção endodôntica e, possivelmente, desempenham papel importante na patogênese da lesão periapical. Dessa forma, o quadro observado nos grupos tratados com aPDT, caracterizados por um atraso no processo de reparo, possivelmente ocorreu também devido à manutenção da sinalização pró-reabsortiva, comparativamente ao grupo tratado com pasta à base de hidróxido de cálcio.

Além disso, no presente estudo, o selamento biológico apical não foi obtido em nenhum dos dois grupos tratados com aPDT e o percentual de redução da lesão periapical foi estatisticamente menor, em comparação aos grupos tratados com pasta à base de hidróxido de cálcio.

Esse atraso no processo de reparo poderia ser atribuído aos efeitos danosos da aPDT, possivelmente relacionados à intensidade de luz, ao fotossensibilizador e à interação desses dois fatores. Além disso, o efeito desta terapia, em Endodontia, pode 
ser prejudicado pela anatomia complexa dos túbulos dentinários e curvatura dos canais radiculares que poderiam impedir a propagação da luz. Assim, sugere-se a realização de estudos adicionais, a fim de se determinar o efeito da aPDT, em diferentes parâmetros de aplicação, inclusive em tecidos sadios, com ausência de infecção. 


\section{Conclusão}





\section{Conclusão}

Tendo em vista a metodologia utilizada e os resultados obtidos, pode-se concluir que, o tratamento em duas sessões com o uso de curativo de demora à base de hidróxido de cálcio promoveu maior redução no tamanho das lesões periapicais e estágio mais avançado de reparo, evidenciado pelos melhores resultados histopatológicos, imunohistoquímicos e radiográficos, em comparação ao tratamento em uma única sessão com utilização do protocolo de aPDT avaliado. 

Referênciass 



\section{ReferênCiAS}

1. Allard U, Stromberg U, Stromberg T. Endodontic treatment of experimentally induced apical periodontitis in dogs. Endod Dent Traumatol. 1987; 3(5):240-4.

2. Anić I, Tachibana H, Masumoto K, Qi P.Permeability, morphologic and temperature changes of canal dentine walls induced by Nd: YAG, CO2 and argon lasers. Int Endod J. 1996; 29(1):13-22.

3. Assed S, Ito IY, Leonardo MR, Silva LAB, Lopatin DE. Anaerobic microorganisms in root canals of human teeth with chronic apical periodontitis detected by indirect immunofluorescence. Endod Dent Traumatol. 1996; 12(2):66-9

4. Bezerra da Silva RA, Nelson-Filho P, Lucisano MP, De Rossi A, de Queiroz AM, Bezerra da Silva LA. MyD88 knockout mice develop initial enlarged periapical lesions with increased numbers of neutrophils. Int Endod J. 2014; 47(7):67586.

5. Borsatto MC, Correa-Afonso AM, Lucisano MP et al. One-session root canal treatment with antimicrobial photodynamic therapy (aPDT): an in vivo study. Int Endod J. 2016; 49(6):511-8.

6. Bouillaguet S, Wataha JC, Zapata O, Campo M, Lange N, Schrenzel J. Production of reactive oxygen species from photosensitizers activated with visible light sources available in dental offices. Photomed Laser Surg. 2010; 28(4):519-25.

7. Chrepa V, Kotsakis GA, Pagonis TC, Hargreaves KM. The effect of photodynamic therapy in root canal disinfection: a systematic review. J Endod. 2014; 40: 891898.

8. Cohenca N, Romualdo PC, da Silva LA, da Silva RA, de Queiroz AM, De Rossi A, Nelson-Filho P. Tissue response to root canal irrigation systems in dogs' teeth with apical periodontitis. Clin Oral Investig. 2015; 19(5):1147-56.

9. da Frota MF, Guerreiro-Tanomaru JM, Tanomaru-Filho M, Bagnato VS, Espir CG, Berbert FL. Photodynamic therapy in root canals contaminated with Enterococcus faecalis using curcumin as photosensitizer. Lasers Med Sci. 2015; 30(7):1867-72.

10. da Silva LA, Leonardo MR, da Silva RS, Assed S, Guimarães LF. Calcium hydroxide root canal sealers: evaluation of $\mathrm{pH}$, calcium ion concentration and 
conductivity. Int Endod J. 1997; 30(3):205-9.

11. da Silva RA, Ferreira PD, De Rossi A, Nelson-Filho P, Silva LA.Toll-like receptor 2 knockout mice showed increased periapical lesion size and osteoclast number. J Endod. 2012; 38(6):803-13

12. De Almeida JM, Theodoro LH, Bosco AF, Nagata MJ, Bonfante S, Garcia VG. Treatment of experimental periodontal disease by photodynamic therapy in rats with diabetes. J Periodontol. 2008; 79:2156-2165.

13. De Rossi A, Fukada SY, De Rossi M, da Silva RA, Queiroz AM, Nelson-Filho P, da Silva LA. Cementocytes Express Receptor Activator of the Nuclear Factor KappaB Ligand in Response to Endodontic Infection in Mice. J Endod. 2016 Jun 21. doi: 10.1016/j.joen.2016.05.009. [Epub ahead of print]

14. De Rossi A, Rocha LB, Rossi MA. Interferon-gamma, Interleukin-10, intercellular adhesion molecule-1, and chemokine receptor 5, but not interleukin-4, attenuate the development of periapical lesions. J Endod. 2008; 34 (1):31-8.

15. Desai S, Chandler N. Calcium hydroxide-based root canal sealers: a review. J Endod. 2009; 35(4):475-80.

16. Dougherty TJ, Gomer CJ, Henderson BW, Jori G, Kessel D, Korbelik M, Moan J, Peng Q. Photodynamic therapy. J Natl Cancer Inst. 1998; 17;90(12):889-905.

17. Dougherty TJ, Gomer CJ, Henderson W, Jori G, Kessel D, Korbelik M, Moan J, Peng Q. Photodinamic therapy. J Natl Cancer Inst 1998: 90:889-905.

18. Faria G, Nelson-Filho P, Freitas AC, Assed S, Ito IY. Antibacterial effect of root canal preparation and calcium hydroxide paste (Calen) intracanal dressing in primary teeth with apical periodontitis. J Appl Oral Sci. 2005; 13(4):351-5.

19. Ferreira PDF. Ausência do receptor Toll-like 2 ocasionou a formação de lesões periapicais mais extensas e com maior número de osteoclastos em camundongos. 2011. Dissertação - Faculdade de Odontologia de Ribeirão Preto, Universidade de São Paulo, Ribeirão Preto, Brasil.

20. Fimple JL, Fontana CR, Foschi F, Ruggiero K, Song X, Pagonis TC, Tanner AC, Kent R, Doukas AG, Stashenko PP, Soukos NS. Photodynamic treatment of endodontic polymicrobial infection invitro. J Endod. 2008; 34(6):728-34.

21. Fonseca MB, Junior PO, Pallota RC, Filho HF, Denardin OV, Rapoport A, Dedivitis RA, Veronezi JF, Genovese WJ, Ricardo AL. Photodynamic therapy for root 
canals infected with Enterococcus faecalis. Photomed Laser Surg. 2008; 26(3):209-13.

22. Foschi F, Fontana CR, Ruggiero K, Riahi R, Vera A, Doukas AG, Pagonis TC, Kent $\mathrm{R}$, Stashenko PP, Soukos NS. Photodynamic inactivation of Enterococcus faecalis in dental root canals in vitro. Lasers Surg Med 2007; 39(10):782-7.

23. Garcez AS, Nuñez SC, Hamblim MR, Suzuki H, Ribeiro MS. Photodynamic therapy associated with conventional endodontic treatment in patients with antibiotic-resistant microflora: a preliminary report. J Endod. 2010; 36(9):14636.

24. Garcez AS, Nunez SC, Hamblin MR, Ribeiro MS. Antimicrobial effects of photodynamic therapy on patients with necrotic pulps and periapical lesion. J Endod. 2008; 34(2):138-42.

25. Garcia V, Longo M, Fernandes LA, Gualberto-Júnior EC, Santinoni CS, Bosco AF, Nagata $\mathrm{MJH}$, Theodoro $\mathrm{LH}$. Effect of the concentration of phenotiazine photosensitizers in antimicrobial photodynamic therapy on bone loss and the immune inflammatory response of induced periodontitis in rats. J Periodontol Res. 2014; 49: 584-594.

26. George S, Kishen A. Influence of photosensitizer solvent on the mechanisms of photoactivated killing of Enterococcus faecalis. Photochem Photobiol. 2008; 84(3):734-40

27. Gursoy H, Ozcakir-Tomruk C, Tanalp J, Yilmaz S. Photodynamic therapy in dentistry: a literature review. Clin Oral Investig. 2013; 17(4):1113-25.

28. Haimovich B, Calvano J, Haimovich AD, Calvano SE, Coyle SM, Lowry SF. In vivo endotoxin synchronizes and suppresses clock gene expression in human peripheral blood leukocytes. Crit Care Med. 2010; 38(3):751-8.

29. Hamblin MR, Hasant T. Photodynamic therapy: a new antimicrobial approach to infectious disease? Photochem Photobiol Sci. 2004; 3:436-450.

30. Harris F, Chatfield LK, Phoenix DA. Phenotiazinium based photosensitizers: photodynamic agents with a multiplicity of cellular targets and clinical applications. Curr Drug Targets. 2005; 6:615-627.

31. Hayek RR, Araújo NS, Gioso MA, Ferreira J, Baptista-Sobrinho CA, Yamada AM, Ribeiro MS. Comparative study between the effects of photodynamic therapy 
and conventional therapy on microbial reduction in ligature-induced periimplantitis in dogs. J Periodontol. 2005; 76(8):1275-81.

32. ISO 7405:2008(E) -Dentistry - Evaluation of biocompatibility of medical devices used in dentistry -International Standards Organization; 2008.

33. Komerik N, Curnow A, MacRobert AJ, Hopper C, Speight PM, Wilson M. Fluorescence biodistribution and photosensitising activity of toluidine blue $\mathrm{O}$ on rat buccal mucosa. Lasers Med Sci. 2002; 17:86-92.

34. Komerik N, MacRobert AJ. Photodynamic therapy as an alternative antimicrobial modality for oral infections. J Environ Pathol Toxicol Oncol. 2006; 25(1-2):487504.

35. Komerik N, Nakanishi H, Robert MAJ, Henderson B, Wilson M. In vivo killing of Porphyromonas gingivalis by toluidine blue photosensitization in an animal model. Antimicrob Agents Chemother. 2003; 47(3): 932-940.

36. Komerik, N., Wilson, M., Poole, S. The effect of photodynamic action on two virulence factors of gram-negative bacteria. Photochem Photobiol. 2000; 72:676-680.

37. Kranz S, Guellmar A, Völpel A, Gitter B, Albrecht V, Sigusch BW. Photodynamic suppression of Enterococcus faecalis using the photosensitizer mTHPC. Lasers Surg Med. 2011; 43(3):241-8.

38. Leonardo MR, Leonardo RT. Tratamento de canais radiculares: Avanços tecnológicos de uma endodontia minimamente invasiva e reparadora. São Paulo: Artes Médicas; 2012.

39. Leonardo MR, Rossi MA, Bonifacio KC, da Silva LA, Assed S. Scanning electron microscopy of the apical structure of human teeth. Ultrastruct Pathol. 2007; 31(4):321-5.

40.Leonardo MR, Rossi MA, Silva LA, Ito IY, Bonifacio KC. EM evaluation of bacterial biofilm and microorganisms on the apical external root surface of human teeth. J Endod. 2002; 28(12):815-8.

41. Leonardo MR. Endodoncia: Tratamiento de conductos radiculares. Principios tecnicos y biologicos. 1. ed. Sao Paulo: Artes Medicas, 2005.

42. Maisch T, Bosl C, Szeimies RM, Lehn N, Abels C. Photodynamic effects of novel XF porphyrin derivatives on prokaryotic and eukaryotic cells. Antimicrob Agents 
Chemother. 2005; 49(4):1542- 52.

43. Malik, Z., Hanania, J., Nitzan, Y. Bactericidal effect of photoactivated porphyrins - an alternative approach to antimicrobial drugs. J Photochem Photobiol. 1990; 5:281-293.

44. Manhart MJ. The calcium hydroxide method of endodontic sealing. Oral Surg Oral Med Oral Pathol. 1982; 54(2):219-24.

45. Mohammadi Z, Dummer PM. Properties and applications of calcium hydroxide in endodontics and dental traumatology. Int Endod J. 2011; 44:697-730.

46. Montagner F, Cintra LTA, Almeida JFA, Ferraz CCR, Zaia AA, Souza-Filho FJ, Gomes BPFA. Estudo in vitro da manutenção da ação antimicrobiana de medicações intracanal frente a cepas de Enterococcus faecalis. Braz Oral Res. 2007; 21: 234-4.

47. Nelson-Filho P, Leonardo MR, Silva LA, Assed S. Radiographic evaluation of the effect of endotoxin (LPS) plus calcium hydroxide on apical and periapical tissues of dogs. J Endod. 2002; 28(10):694-6.

48. Ng R, Singh F, Papamanou DA, Song X, Patel C, Holewa C, Patel N, Klepac-Ceraj V, Fontana CR, Kent R, Pagonis TC, Stashenko PP, Soukos NS. Endodontic Photodynamic Therapy Ex Vivo. J Endod. 2011; 37(2):217-22.

49. Novaes AB Jr, Schwartz-Filho HO, de Oliveira RR, Feres M, Sato S, Figueiredo LC. Antimicrobial photodynamic therapy in the non-surgical treatment of aggressive periodontitis: microbiological profile. Lasers Med Sci. 2012; 27(2):389-95.

50. Oliveira LD, Leão MV, Carvalho CA, Camargo CH, Valera MC, Jorge AO, Unterkircher CS. In vitro effects of calcium hydroxide and polymyxin B on endotoxins in root canals. J Dent. 2005; 33(2):107-14

51. Oliveira RR, Schwartz-Filho HO, Novaes AB Jr, Taba M Jr. Antimicrobial photodynamic therapy in the non-surgical treatment of aggressive periodontitis: a preliminary randomized controlled clinical study. J Periodontol. 2007; 78(6):965-73.

52. Paula-Silva FW, Ghosh A, Arzate H, Kapila S, da Silva LA, Kapila YL. Calcium hydroxide promotes cementogenesis and induces cementoblastic differentiation of mesenchymal periodontal ligament cells in a CEMP1- and ERK-dependent 
manner. Calcif Tissue Int. 2010; 87(2):144-57.

53. Profio AE, Doiron DR. Transport of light in tissue in photodynamic therapy. Photochem Photobiol. 1987; 46:591-599.

54. Qin YL, Luan XL, Bi LJ, Sheng YQ, Zhou CN, Zhang ZG. Comparison of toluidine blue-mediated photodynamic therapy and conventional scaling treatment for periodontitis in rats. J Periodontal Res. 2008; 43:162-167

55. Rocha CT, Rossi MA, Leonardo MR, Rocha LB, Nelson-Filho P, Silva LA. Biofilm on the apical region of roots in primary teeth with vital and necrotic pulps with or without radiographically evident apical pathosis. Int Endod J. 2008; 41(8):664-9.

56. Saatchi M, Shokraneh A, Navaei H, Maracy MR, Shojaei H. Antibacterial effect of calcium hydroxide combined with chlorhexidine on Enterococcus faecalis: a systematic review and meta-analysis. J Appl Oral Sci. 2014; 22:356-65.

57. Sathorn C, Parashos P, Messer H. Australian endodontists' perceptions of single and multiple visit root canal treatment. Int Endod J. 2009; 42: 811-8.

58.Schröder U. Effects of calcium hydroxide-containing pulp-capping agents on pulp cell migration, proliferation, and differentiation. J Dent Res. 1985; 64 Spec No:541-8.

59. Seal GJ, Ng YL, Spratt D, Bhatti M, Gulabivala K. An in vitro comparison of the bactericidal efficacy of lethal photosensitization or sodium hypochlorite irrigation on streptococcus intermedius biofilms in root canals. Int Endod J. 2002; 35:26874.

60.Sharman WM, Allen CM, van Lier JE. Photodynamic therapeutics: basic principles and clinical applications. Drug Discov Today. 1999; 4(11):507-517.

61.Shovelton DS. The presence and distribution of microorganisms within non-vital teeth. Br Dent J. 1964; 117:101-7.

62. Silva LA, Nelson-Filho P, Leonardo MR, Rossi MA, Pansani CA. Effect of calcium hydroxide on bacterial endotoxin in vivo. J Endod. 2002; 28(2):94-8.

63.Silva LA, Silva RA, Branco LG, Navarro VP, Nelson-Filho P. Quantitative radiographic evaluation of periapical bone resorption in dog's teeth contaminated with bacterial endotoxin (LPS) associated or not with calcium 
hydroxide. Braz Dent J. 2008; 19(4):296-300.

64. Silva LAB, Novaes Jr AB, liveira RR, Nelson-Filho P, Santamaria Jr M, Silva RAB. Antimicrobial Photodynamic Therapy for the Treatment of Teeth with Apical Periodontitis: A Histopathological Evaluation. JOE. 2012; 38(3): 360-6.

65. Silva $L A B$, Silva RAB, Nelson-Filho $P$, Cohenca $N$. Intracanal medication in root canal disinfection. In: Nestor Cohenca. (Org.). Disinfection of Root Canal Systems: The Treatment of Apical Periodontitis. 1ed.New Jersey: WileyBlackwell. 2014; 1:247-275.

66. Siqueira JF Jr, Rôças IN. Microbiology and treatment of acute apical abscesses.Clin Microbiol Rev. 2013; 26(2):255-73.

67. Sjögren U, Figdor D, Persson S, Sundqvist G. Influence of infection at the time of root filling on the outcome of endodontic treatment of teeth with apical periodontitis. Int Endod J. 1997; 30(5):297-306.

68. Soukos NS, Chen PS, Morris JT, Ruggiero K, Abernethy AD, Som S, Foschi F, Doucette S, Bammann LL, Fontana CR, Doukas AG, Stashenko PP. Photodynamic therapy for endodontic disinfection. Endod. 2006; 32(10):979-84 69. Souza LC, Brito PRR, Oliveira JCM, Alves FRF, Moreira EJL, Sampaio-Filho $\mathrm{HR}$ et al. 9. Photodynamic therapy with two different photosensitizers as a supplement to instrumentation irrigation procedures in promoting intracanal reduction of Enterococcus faecalis. J Endod. 2010; 2:292-6.

70. Spikes, J.D., Jori, G. Photodynamic therapy of tumours and other diseases using porphyrins. Lãs Med Sc. 1987; 2:3-15.

71. Susila AV, Sugumar R, Chandana CS, Subbarao CV. Combined effects of photodynamic therapy and irrigants in disinfection of root canals. J Biophotonics. 2016; 9(6):603-9.

72. Tanomaru JM, Leonardo MR, Tanomaru-Filho M, Silva LA, Ito IY. Microbial distribution in the root canal system after periapical lesion induction using different methods. Braz Dent J. 2008; 19(2):124-9.

73. Trindade AC, De Figueiredo JA, Steier L, Weber JB. Photodynamic therapy in endodontics: a literature review. Photomed Laser Surg. 2015; 33:175-182.

74. Upadya $\mathrm{MH}$, Kishen $\mathrm{A}$. Influence of bacterial growth modes on the susceptibility 
to light-activated disinfection. Int Endod J. 2010; 43:978-987.

75. Vahabi S, Fekrazad R, Ayremlou S, Taheri S, Zangeneh N. The Effect of Antimicrobial Photodynamic Therapy with Radachlo-rin and Toluidine Blue on Streptococcus Mutans: An in Vitro Study. Journal of Dentistry, Tehran University of Medical. 2011; 8(2):48-54.

76. Vera J, Siqueira JF Jr, Ricucci D, Loghin S, Fernández N, Flores B, Cruz AG. Oneversus two-visit endodontic treatment of teeth with apical periodontitis: a histobacteriologic study. J Endod. 2012; 38(8):1040-52.

77. Wainwright, M. Photodynamic chemotherapy (PACT). J Antimicrob Chemother. 1998; 42(1):13-28.

78. Xhevdet A, Stubljar D, Kriznar I, Jukic T, Skvarc M, Veranic P, Ihan A. The disinfecting efficacy of root canals with laser photodynamic therapy. J Lasers Med Sci. 2014; 5(1):19-26.

79. Yildirim C, Karaarslan ES, Ozsevik S, Zer Y, Sari T, Usumez A. Antimicrobial efficiency of photodynamic therapy with different irradiation durations. Eur J Dent. 2013; 7(4):469-73. 
Anexo 



\section{AneXo A}

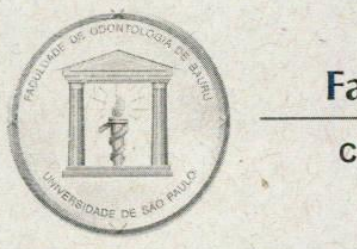

Universidade de São Paulo Faculdade de Odontologia de Bauru

Comissão de Ética no Ensino e Pesquisa em Animais

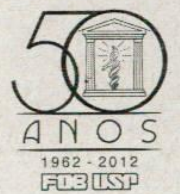

CEEPA-Proc. № 19/2012

Bauru, 24 de setembro de 2012.

Senhor Professor,

O projeto de pesquisa encaminhado a esta Comissão de Ética no Ensino e Pesquisa em Animais, denominado Terapia fotodinâmica antimicrobiana no tratamento da periodontite periapical induzida experimentalmente, de autoria de Léa Assed Bezerra da Silva e Arthur Belém de Novaes Jr., Paulo Nelson Filho, Raquel Assed Bezerra da Silva e Lídia Regina da Costa Hidalgo, foi enviado ao relator para avaliação e considerado APROVADO "ad referendum" desta Comissão, nesta data.

Atenciosamente,

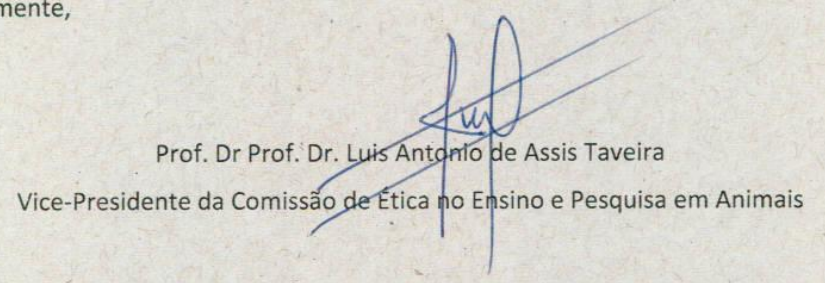

Profa Dra Lea Assed Bezerra da Silva

Docente do Departamento de Clínica Infantil, Odontologia Preventiva e Social - FMRP/USP

Al. Dr. Octávio Pinheiro Brisolla, 9-75 - Bauru-SP - CEP 17012-101 - C.P. 73 e-mail: mferrari@fob.usp.br - Fone/FAX (0xx14) 3235-8356

http://www.fob.usp.br 

Apêndice 

APÊNDICE 1

Assunto: Decision on your manuscript \#LIMS-D-1600019R2

Data: $\quad 24$ Jun 2016

We are pleased to inform you that your manuscript, "Comparison between onesession root canal treatment with aPDT and two-session treatment with calcium hydroxide based antibacterial dressing, in dog's teeth with apical periodontitis" has been accepted for publication in Lasers in Medical Science.

For queries regarding your accepted paper, please click the following link http://www.springer.com/10103; then click on "Contacts", and then "Production Editor", complete the query form and click "Submit".

Please remember to always include your manuscript number, \#LIMS-D-16-00019R2, whenever inquiring about your manuscript. Thank you.

Best regards,

Keyvan Nouri

Lasers in Medical Science 


\title{
Comparison between one-session root canal treatment with aPDT and two-session treatment with calcium hydroxide based antibacterial dressing, in dog's teeth with apical periodontitis
}

Lidia Regina da Costa Hidalgo ${ }^{1}$, Léa Assed Bezerra da Silva ${ }^{1}$, Paulo Nelson-Filho ${ }^{1}$, Raquel Assed Bezerra da Silva ${ }^{1}$, Fabrício Kitazono de Carvalho ${ }^{1}$, Marília Pacífico Lucisano ${ }^{1}$, Arthur Belem Novaes $\mathrm{Jr}^{2}$

${ }^{1}$ Department of Pediatric Dentistry, School of Dentistry of Ribeirão Preto, University of São Paulo, Ribeirão Preto, SP, Brazil

${ }^{2}$ Department of Bucco-Maxilo-Facial Surgery and Traumatology and Periodontology, School of Dentistry of Ribeirão Preto, University of São Paulo, Ribeirão Preto, SP, Brazil

\begin{abstract}
:
Aims: To evaluate one-session endodontic treatment with aPDT and two-session treatment with calcium-hydroxide $(\mathrm{CH})$-based dressing in dog's teeth with apical periodontitis. Methods: After experimental induction of apical periodontitis, 48 teeth were randomly assigned to the following groups: Groups OS/aPDT120d and OS/aPDT180d (one-session treatment with aPDT) and Groups TS/CH120d and TS/CH 180d (two-session treatment with CH-based dressing - control groups). The animals were euthanized after 120 and 180 days. After histotechnical processing, microscopic and radiographic analyses were performed. Data were analyzed by Kruskal-Wallis and Fisher's exact tests $(\alpha=0.05)$. Results: Groups TS/CHs presented repaired resorbed cemental areas, with collagen bundles and few inflammatory cells. In groups OS/aPDTs, the areas of cemental resorption were not repaired with reduced presence of cells and fibers. In the analysis of the apical closure, fluorescence microscopy and percentage of radiographic reduction of lesions, there was significant difference between groups TS/CH120d and OS/aPDT120d and between TS/CH180d and OS/aPDT180d ( $<<0.05)$. Groups
\end{abstract}


TS/CHs had weak RANKL expression and positive immunostaining for RANK and OPG. In OS/aPDT120d, there was positive immunostaining for RANKL. In OS/aPDT180d, the three osteoclastogenesis markers were expressed. Conclusion: The results using aPDT were worse than those obtained with two-session endodontic treatment using a $\mathrm{CH}$-based dressing in teeth with apical periodontitis.

Keywords: Photodynamic therapy; apical periodontitis; root canal treatment; calcium hydroxide.

\section{Introduction}

The elimination of root canal system infection in teeth with pulp necrosis and apical periodontitis is directly related to endodontic treatment success [1,2]. It has been consistently demonstrated that the use of an antibacterial interappointment agent during root canal treatment of teeth with apical periodontitis offers a higher success rate compared to one-visit treatment. It is also necessary to maximize bacterial reduction before filling to enhance periapical repair $[3,4]$.

Currently, efforts have been directed to seek adjunct alternatives that can be incorporated to the one-session root canal treatment in order to achieve a level of success in endodontic disinfection comparable or even better than demonstrated with the use of an intracanal dressing between two or multiple root canal treatment sessions. One such effort is the antimicrobial photodynamic therapy (aPDT) that recently was introduced in Endodontics and has been considered a promising strategy [5-9].

aPDT is defined as "the light-induced inactivation of cells, microorganisms and molecules"[6], based on the use of a nontoxic photosensitizing agent, a photosensitizer (PS). When activated by low-energy light of the appropriate wavelength in the presence of oxygen, the PS generates a cascade of oxidative photochemical events that results in the production of 
reactive oxygen species (ROS), such as singlet oxygen, superoxides and free radicals $[7,8,10]$. These highly reactive cytotoxic species are known to cause irreversible damage to various essential intracellular molecules of bacterial cells, ultimately resulting in the death of microorganisms targeted by the PS $[6,7,11]$.

The effect and the extent of tissue damage of aPDT to target tissues depend on several factors, such as type, dose, application time and location of the PS; availability of oxygen; and parameters relating to the light source, including the wavelength $(\mathrm{nm})$, power density $\left(\mathrm{mW} / \mathrm{cm}^{2}\right)$ and energy fluence $\left(\mathrm{J} / \mathrm{cm}^{2}\right)$ [7]. Thus, a number of variables can influence the outcome of this therapy [9]. Recent research suggests the need for additional studies to optimize and standardize the aPDT clinical protocol $[7,8]$, in order to obtain a powerful antimicrobial effect without causing damage to the host's surrounding healthy tissues.

The efficacy of aPDT in endodontic therapy has been extensively evaluated in vitro, ex vivo, in vivo [9,12-22] and has been the subject of literature reviews [7,8]. Although promising results have been reported, there are conflicting results that show limitations of this therapy. As demonstrated by Meire et al. (2012) [18], aPDT systems were unable to promote an efficient reduction in Enterococcus faecallis cells in vitro, which does not ensure their effectiveness against biofilms. Therefore, there is no sufficient scientific evidence to support the use of aPDT instead of standard endodontic treatment for root canal disinfection.

Low-level lasers are the most frequently used light sources because they are monochromatic in a wavelength specific for activation of the PS in aPDT protocols. [6,23]. The use of intracanal optical fibers is recommended to increase the efficacy of aPDT for endodontic applications [24]. Helbo (Bredent Medical, Senden, Germany) has developed a specific system for aPDT applications in Endodontics, which allows a three-dimensional laser exposure in the entire canal length through a flexible optical fiber tip. Additionally, the PS is delivered from a 
disposable plastic applicator, which facilitates the application of the agent within the canal. To the best of our knowledge, this is the first in vivo study to evaluate this system in Endodontics.

The authors of previous studies [5,9] with evaluation periods of 90 days or shorter suggested that a progression of the repair process could be observed after longer evaluation periods. Therefore, the aim of this in vivo study was to evaluate comparatively one-session root canal treatment with aPDT and two-session treatment with calcium hydroxide $(\mathrm{CH})$-based antibacterial dressing in dog's teeth with apical periodontitis, after 120- and 180-day evaluation periods. The hypothesis was that the use of aPDT as an adjunctive to conventional treatment for endodontic disinfection in a single session could provide a beneficial effect, resulting in a periapical repair similar to that provided by the $\mathrm{CH}$-based intracanal dressing after longer evaluation periods.

\section{Materials and Methods}

All animal procedures were performed according to the Animal Research Ethics Committee of the School of Dentistry of Bauru, University of São Paulo - Brazil (Process number 19/2012). Also, the present study was based on the protocol recommended by the ISO (ISO standard 7405:1997) [25].

This study was conducted on 96 root canals (48 teeth) from second and third maxillary premolars and second, third and fourth mandibular premolars of six 12-month-old mongrel dogs weighing $15 \mathrm{~kg}$ on average, distributed into 4 groups.

\section{Operative Procedures}

The protocol used for induction of apical periodontitis has been described previously [5]. Briefly, the animals were preanesthetized 15 minutes before the operative procedures and received inhalation anesthesia with isoflurane (Abbott Laboratories, St Laurent, QC, Canada). 
After pulp tissue removal, canals were left exposed to the oral cavity for 7 days to allow microbial contamination. After this period, the coronal accesses were sealed with zinc oxideeugenol cement with no canal treatment to induce apical periodontitis. Radiographs were taken before the operative procedures and thereafter at 15-day intervals until periapical radiolucencies developed, which usually occurred after 45 days.

After the induction of apical periodontitis, the teeth were isolated with a rubber dam, the operative field was disinfected with $2 \%$ chlorhexidine gluconate, and the septic-toxic content of the canals was removed in a pressureless crown-down manner with concomitant $2.5 \% \mathrm{NaOCl}$ irrigation. Size 15 to $25 \mathrm{~K}$-files (Dentsply Maillefer, Ballaigues, Switzerland) were used sequentially at the radiographic apex under irrigation at each instrument change for debridement and standardization of the apical opening. Working length (WL) was established $1 \mathrm{~mm}$ short of the radiographic apex. Then, the canals were instrumented using the Pro-Taper NiTi rotatory Universal System powered by the X-Smart endodontic micromotor (Dentsply Maillefer) $1 \mathrm{~mm}$ short of the radiographic apex and flushed with $3.6 \mathrm{~mL} 2.5 \% \mathrm{NaOCl}$ at each change of instrument. Next, the canals were dried by suction and sterile paper points.

To test all variables in the same animal but in different quadrants, every hemiarch was subjected to the different treatment protocols according to a random changeover system. Four groups were formed according to the following experimental conditions:

Groups TS/CH $120 \mathrm{~d}$ and $\mathrm{TS} / \mathrm{CH}_{180 \mathrm{~d}}$ (two-session root canal treatment - $\mathrm{CH}$-based antibacterial dressing - control groups): After cleaning and shaping, the root canals were filled with a commercial CH-based paste $\left(\right.$ Calen $^{\circledR}$; S.S. White Artigos Dentarios Ltda., Rio de Janeiro, Brazil) using a 27-G long needle, up to the limit of radiographic apex. The Calen paste is composed of $2.5 \mathrm{~g} \mathrm{CH}, 0.5 \mathrm{~g}$ zinc oxide p.a. $0.05 \mathrm{~g}$ colophony and $2 \mathrm{~mL}$ polyethylene glycol 400 (vehicle). The coronal restoration was achieved with glass-ionomer-based cement for 15 days. At the end of this period and with rubber dam isolation in place, the canal dressing was 
removed by successive flushes with $2.5 \% \mathrm{NaOCl}$, and EDTA solution was applied for 3 min. Root filling was performed with AH Plus sealer (De Trey; Dentsply, Konstanz, Germany) and gutta-percha cones by cold lateral condensation. The teeth were restored with a glass-ionomer cement base and silver amalgam.

Groups OS/aPDT $120 \mathrm{~d}$ and OS/aPDT $180 \mathrm{~d}$ (one-session root canal treatment with aPDT): After cleaning and shaping, the PS (phenothiazine chloride at $10 \mathrm{mg} / \mathrm{mL}$ concentration; $70 \mu \mathrm{L}$ volume; HELBO Blue Photosensitizer; Helbo Photodynamic Systems GmbH \& Co KG, Grieskirchen, Austria) was applied inside the root canal with an endodontic needle apically to coronally and left to react for 1 minute. After this time, the root canals were rinsed with sterile distilled water to remove the excess, dried with paper points, and irradiated with a laser source. A 660 -nm wavelength handheld battery-operated diode laser with $20 \mathrm{~mW}$ power output and 60 $\mathrm{mW} / \mathrm{cm}^{2}$ irradiance (HELBO Therapielaser, Helbo Photodynamic Systems GmbH \& Co KG) was used. The laser was delivered through flexible fiberoptic tip with $0.6 \mathrm{~mm}$ diameter (HELBO 3D Pocket Probe, Helbo Photodynamic Systems GmbH \& Co KG), with fiber spot area equivalent to $0.002 \mathrm{~m}^{2}, 0.06 \mathrm{~W}$ output power and 3.6 J energy. During irradiation, the fiber was placed within the root canal at the WL. The fiber design permits a 3-dimensional exposure of the area, emitting light at the tip and from the lateral sides, thus leading to even light distribution both vertically and horizontally. The laser application covered $2 \mathrm{~mm}$ per second, using a vertical movement from the apex towards the cervical region, as described previously [26]. The photosensitizer was irradiated as recommended by the manufacturer during 1 minute in a continuous wave mode. The fluence delivered to the PS was $1.800 \mathrm{~J} / \mathrm{cm}^{2}$. Canals were irrigated with saline, dried with sterile absorbent paper points, and filled in the same session with AH Plus sealer (Dentsply, De Trey, Konstanz, Germany) and gutta-percha cones. The pulp chambers were cleaned, a restorative glass ionomer cement base was prepared, and the access cavities were restored with silver amalgam, as described for the other groups. 
The animals were euthanized after 120 (Groups TS/CH $\mathrm{CH}_{120 \mathrm{~d}}$ and OS/aPDT $120 \mathrm{~d}$ ) and 180 days (Groups $\mathrm{TS} / \mathrm{CH}_{180 \mathrm{~d}}$ and OS/aPDT $180 \mathrm{~d}$ ). The maxillas and mandibles with teeth were dissected and sectioned to obtain individual roots, which were fixed in $10 \%$ buffered formalin for 48 hours, demineralized in EDTA, and embedded in paraffin. Sagittal 5-mm-thick serial sections were obtained, stained with hematoxylin and eosin and Mallory trichrome staining techniques, and examined under light microscopy by an experienced examiner blinded to the groups. A descriptive and quantitative microscopic analysis was performed using an AXIO IMAGER.M1 microscope (Carl Zeiss, Jena, Germany) coupled to an AXIOCAM MRc5 camera (Carl Zeiss).

Descriptive Qualitative Analysis of Apical, and Periapical Features under Conventional Light Microscopy

A description of the characteristics of the apical and periapical region of each group was done according to the following histopathological parameters: newly formed apical mineralized tissue, periapical inflammatory infiltrate, apical periodontal ligament thickness, and mineralized tissue resorption (ie, cementum and bone) $[5,27]$.

Semi-Quantitative Microscopic Analysis

A semi-quantitative microscopic analysis was performed using a score system, according to the following parameters: periodontal ligament (PDL) thickness: 0 . Normal, 1. Slightly increased, 2. Moderately increased, 3. Severely increased; Intensity of the inflammatory infiltrate: 0. Absent, 1. Mild, 2. Moderate, 3. Severe; Cementum and alveolar bone resorption: 0. Absent, 1. Present; apical closure by deposition of mineralized tissue after endodontic treatment: 0. Absent, 1. Partial, 2. Total.

Morphometric Analysis of Periapical Lesion Size under Fluorescence Microscopy

Morphometric evaluation of periapical lesion size was performed on the HE-stained specimens using Axio Imager.M1 fluorescence microscope at 1.25× magnification [5,28,29]. 
For every specimen, the extent (area) of the periapical lesion was delimited and measured in square millimeter, using the Axio Vision Rel 4.8 software. Delimitation of the lesion excluded the intact areas (periodontal ligament, cementum and alveolar bone), easily identified by their strong green fluorescence, and included resorption areas and inflammatory infiltrate, identified by absence of fluorescence and a darkened appearance.

\section{Radiographic Analysis}

Radiographs were taken in a standardized manner at the beginning of the treatment (day 0) and new radiographs were taken 120 days (Groups TS/ $\mathrm{CH}_{120 \mathrm{~d}}$ and OS/aPDT $120 \mathrm{~d}$ ) and 180 days (TS/CH ${ }_{180 \mathrm{~d}}$ and $\mathrm{OS}_{\mathrm{aPDT}} \mathrm{T}_{180 \mathrm{~d}}$ ) after root canal filling. Custom-made film-holding devices were employed in all radiographic shots. A Heliodent dental x-ray machine (Siemens; Erlanger, Germany) was used with exposure parameters set at $60 \mathrm{kV}, 10 \mathrm{~mA}$ and $0.4 \mathrm{~s}$. Ultraspeed periapical film (Eastman Kodak, Rochester, NY, USA) was exposed and processed according to the time/temperature method. The images were digitized and transferred to the Image $\mathbf{J}$ software (version $1.28 \mathrm{u}$, National Institutes of Health, Washington, DC, USA), for measurement and recording of results.

For each image pair, the radiolucent areas of apical periodontitis, when present, were demarcated $\left(\mathrm{mm}^{2}\right)$ and measured by a single calibrated examiner, blinded to groups under examination. Delineation was performed on the radiographic image to excluded tooth structure, but included the area of bone rarefaction. The percentage of reduction in the size of the periapical lesions was calculated for each group.

\section{Immunohistochemical Analysis}

The immunohistochemical analysis was performed for the identification of osteoclastogenesis markers (RANK, RANKL, and OPG). The reactions were performed using the avidin-biotin-peroxidase complex (indirect method), as described by Da Silva et al. (2012)[5]. The following primary antibodies were used: anti-RANK (polyclonal rabbit 
antibody H300 sc:9072, 1:700 dilution; Santa Cruz Biotechnology Inc., Dallas, TX, USA), antiRANKL (polyclonal goat antibody n-sc 19:7628; Santa Cruz Biotechnology Inc.; 1:400 dilution) and anti-OPG (polyclonal goat antibody n-sc 20: 8468; Santa Cruz Biotechnology Inc.; 1:700 dilution). The slides were incubated with biotinylated secondary antibody (goat antirabbit IgG-B and SC-2040 and rabbit antigoat Ig G-B and SC-2774; Santa Cruz Biotechnology Inc., 1:200 dilution). The identification of the markers for osteoclastogenesis was performed under reflected light using the Axio Imager.M1 (Zeiss) microscope. Results were expressed in a qualitative manner, considering the presence/absence and localization of immunostaining, as described by Da Silva et al. (2012)[5].

\section{Statistical analysis}

Data from the morphometric and radiographic analyses were analyzed statistically by the nonparametric Kruskal-Wallis test and the semi-quantitative data were analyzed statistically by Fisher's Exact test at a 5\% significance level, using the GraphPad Prism software version 5.0 (GraphPad Software Inc., San Diego, CA, USA).

\section{Results}

Descriptive Qualitative Microscopic Analysis

\section{DAYS}

Group TS/ $\mathrm{CH}_{120 \mathrm{~d}}$ : The apical cementum presented repaired resorption areas, with numerous collagen fiber bundles in the PDL and discrete presence of diffuse inflammatory cells. The PDL space was slightly enlarged.

Group OS/aPDT $120 \mathrm{~d}$ : The specimens exhibited nonrepaired resorption areas in the apical cementum, predominantly mononuclear inflammatory infiltrate, and few delicate collagen fiber bundles. The alveolar bone was frequently denuded. 
Group $\mathrm{TS} / \mathrm{CH}_{180 \mathrm{~d}}$ : The apical cementum presented repaired resorption areas, with numerous collagen fiber bundles in the PDL and scarce diffuse inflammatory cells. In most specimens, the PDL space was normal or slightly enlarged and exhibited an advanced repair process.

Group OS/aPDT $180 \mathrm{~d}$ : The specimens exhibited nonrepaired resorption areas in the apical cementum, mild inflammatory infiltrate with predominantly mononuclear inflammatory cells, and a moderate presence of delicate collagen fiber bundles and young fibroblasts.

Figure 1 illustrates the main histopathological events involved in tissue response to the treatments performed in the four groups.

Semi-Quantitative Microscopic Analysis

\section{DAYS}

The results of the descriptive qualitative microscopic analysis (scores) observed at 120 days are presented in Figure 2.

PDL thickness: There was a statistically significant difference between the groups ( $\mathrm{p}<0.0001$ ). In Group TS/ $\mathrm{CH}_{120 d}$, the PDL space was normal in $10 \%$ of the specimens, slightly enlarged in $60 \%$, moderately enlarged in $30 \%$ and severe enlargement was not observed. In Group OS/aPDT $120 \mathrm{~d}$, the PDL space was slightly enlarged in $20 \%$ of the specimens, moderately enlarged in $70 \%$ and severely enlarged in $10 \%$. None of the specimens presented normal PDL thickness.

Intensity of the inflammatory infiltrate: The results of the groups were significantly different $(\mathrm{p}<0.0001)$. In Group TS/CH $\mathrm{CH}_{120 \mathrm{~d}}, 50 \%$ of the specimens did not exhibit inflammatory cells and the other $50 \%$ presented a mild inflammatory infiltrate. In Group OS/aPDT ${ }_{120 d}$, the inflammatory infiltrate was absent in $40 \%$ of the specimens, mild in $40 \%$, moderate in $15 \%$ and severe in $5 \%$. 
Cementum and alveolar bone resorption: There was a statistically significant difference between the groups $(\mathrm{p}=0.0015)$. In Group $\mathrm{TS} / \mathrm{CH}_{120 \mathrm{~d}}$, none of the specimens exhibited resorption while in Group OS/aPDT $120 \mathrm{~d}$ resorption areas in the apical cementum and alveolar bone were observed in $10 \%$ of the cases.

Apical closure by deposition of mineralized tissue: There was a statistically significant difference between the groups ( $\mathrm{p}=0.0015)$. Group $\mathrm{TS} / \mathrm{CH}_{120 \mathrm{~d}}$ presented absent, partial and total apical closure by deposition of mineralized tissue in $50 \%, 17 \%$ and $33 \%$ of the specimens, respectively. In OS/aPDT 120 , absent and partial apical closure was observed in $95 \%$ and $5 \%$ of the specimens, respectively.

\section{DAYS}

The results of the descriptive qualitative microscopic analysis (scores) observed at 180 days are presented in Figure 3.

PDL thickness: There was a statistically significant difference between the groups ( $\mathrm{p}<0.0001$ ). In Group TS/CH $\mathrm{CH}_{180 \mathrm{~d}}$, the PDL space was normal in $35 \%$ of the specimens, slightly enlarged in $20 \%$, moderately enlarged in $20 \%$ and severely enlarged in $25 \%$. In Group OS/aPDT $_{180 \mathrm{~d}}$, the PDL space was normal in $5 \%$ of the specimens, slightly enlarged in $35 \%$, moderately enlarged in 55\% and severely enlarged in 5\%.

Intensity of the inflammatory infiltrate: There was no statistically significant difference between the groups $(\mathrm{p}=0.6714)$. In Group $\mathrm{TS} / \mathrm{CH}_{180 \mathrm{~d}}, 40 \%$ of the specimens did not exhibit inflammatory cells, $55 \%$ presented a mild inflammatory infiltrate, and 5\% presented a moderate inflammatory infiltrate. In Group OS/aPDT $180 \mathrm{~d}$, the inflammatory infiltrate was absent in $34 \%$ of the specimens, mild in $61 \%$ and moderate in $5 \%$.

Cementum and alveolar bone resorption: The results of the groups were significantly different $(\mathrm{p}=0.0015)$. In Group $\mathrm{TS} / \mathrm{CH}_{180 \mathrm{~d}}, 85 \%$ of the specimens did not exhibit resorption 
while in Group OS/aPDT ${ }_{180 d}$ resorption areas in the apical cementum and alveolar bone were observed in $34 \%$ of the cases.

Apical closure by deposition of mineralized tissue: Statistically significant difference was observed between the groups $(\mathrm{p}<0.0001)$. Group $\mathrm{TS} / \mathrm{CH}_{180 \mathrm{~d}}$ presented absent, partial and total apical closure by deposition of mineralized tissue in 52\%, $29 \%$ and $19 \%$ of the specimens, respectively. In OS/aPDT $180 \mathrm{~d}$, absent and partial apical closure was observed in $89 \%$ and $11 \%$ of the specimens, respctively.

Fluorescence microscopy analysis

Figure 4 (A and B) shows representative images of the periapical lesion areas $\left(\mathrm{mm}^{2}\right)$ under fluorescence microscopy comparing Groups TS/CH $\mathrm{CH}_{120 \mathrm{~d}}$ versus $\mathrm{OS}_{\mathrm{aPDT}} \mathrm{T}_{120 \mathrm{~d}}$ (120 days) and Groups TS/ $\mathrm{CH}_{180 \mathrm{~d}}$ versus OS/aPDT $180 \mathrm{~d}$ (180 days). The statistical analysis revealed a significant difference between the groups euthanized after 120 days $(\mathrm{p}=0.0004)$ and after 180 days $\left(\mathrm{p}=0.0081\right.$ ). For the two evaluation periods, Groups $\mathrm{TS} / \mathrm{CH}_{120 \mathrm{~d}}$ and TS/CH $180 \mathrm{~d}$ ) had significantly smaller periapical lesions than Groups OS/aPDT $120 \mathrm{~d}$ and OS/aPDT $180 \mathrm{~d}$.

\section{Radiographic Analysis}

A significantly greater percent reduction of periapical lesion size was observed in the groups that received a $\mathrm{CH}$-based antibacterial dressing between two root canal treatment sessions at both 120-day $(\mathrm{p}=0.0008)$ and 180 -day $(\mathrm{p}=0.0195)$ evaluation periods (Figure 4C and 4D).

\section{Immunohistochemical Analysis}

120 DAYS

Group TS/CH120d: Weak RANKL immunostaining was detected in the cemental lacunae (cementocytes) and periapical region, especially in the polymorphonuclear cells close to the apical foramen. Positive immunoreactivity to OPG was observed only in few osteoclasts and 
immunostaining was absent in the cemental lacunas. These results indicate reduced proresorption signaling.

Group OS/aPDT $120 \mathrm{~d}$ : Weak RANKL immunostaining was detected in the cemental lacunae and periapical region, especially in the polymorphonuclear cells close to the apical foramen. Positive staining was observed in the cemental lacunae and osteoblasts. Very weak OPG staining was present in the cemental lacunae. RANK expression was weak in the periapical lesion and in some polymorphonuclear and mononuclear cells. These results indicate the presence of pro-resorption signaling.

\section{DAYS}

Group TS/CH 180d: A decrease in RANKL expression in the cemental lacunae was observed compared with the shorter period. Fibroblasts, cementoblasts and osteoblasts were not stained positively for RANKL. OPG immunostaining was observed especially in the polymorphonuclear cells and osteoblasts, with a well-delimited zone of new bone formation, indicating a bone remodeling process. Positive immunoreactivity to RANK was observed for polymorphonuclear cells, whenever they were present.

Group OS/aPDT $180 \mathrm{~d}$ : In the longer period, RANKL immunostaining was maintained in the cemental lacunae and inside the periapical lesion close to the areas of cemental resorption. Osteoclasts present in the periphery of the lesion expressed RANKL, indicating progression of the resorption process or no repair of the areas of resorption. Positive immunoreactivity to OPG was observed in the cemental lacunae and in the mononuclear cells and fibroblasts. Strong RANK staining was observed in the cemental lacunae, with positive immunoreactivity in the osteoclasts and some macrophages close to the apical foramen. The results indicate a delayed repair process due to the maintenance of the pro-resorption signaling in comparison with the group that received a $\mathrm{CH}$ intracanal dressing between two root canal treatment sessions. 
Figure 5 is a composite figure of representative images of the immunohistochemical analysis in each group.

\section{Discussion}

This study was designed to compare the response of dog's teeth with apical periodontitis to endodontic treatment completed in the same session with use of aPDT or completed two sessions after placement of a CH-based medication. It is noteworthy that the groups of twosession treatment with $\mathrm{CH}$-based dressing were considered as a reference (or control), since the mechanisms of action of $\mathrm{CH}$ have been widely investigated [30,31] and literature shows, in histopathological studies, that this protocol provides higher success rates and promotes periapical repair [32].

Although in vitro studies have demonstrated a high antimicrobial effect of aPDT against endodontic pathogens $[16,17,33,34]$ the results still indicate the need for establishing parameters for the safe use of aPDT under clinical conditions in such a way to promote photodynamic inactivation of microorganisms without being harmful to the healthy tissue cells. In addition, the results of in vivo endodontic studies are not yet consistent in indicating the use of aPDT alone to replace the conventional treatment $[5,9]$.

The authors of previous studies with evaluation periods of 90 days or shorter [5,9] hypothesized that repair of the aPDT-treated groups could be observed if a longer evaluation period is allowed. Therefore, in the present study evaluation periods of 120 and 180 days were used. However, our results demonstrate that the root canal treatment using an intracanal dressing between sessions still provides higher success rates than compared with single session with aPDT even after longer periods. Overall, the histopathological results obtained 120 and 180 days after the endodontic treatment using aPDT revealed an evolution in the repair process, since the difference between the groups was less accentuated for some parameters. However, 
even after a long evaluation period, the use of $\mathrm{CH}$-based intracanal dressing promoted significantly better results.

According to Chrepa et al. (2014)[7], several variables can influence endodontic treatment outcome using the aPDT. The delay in the repair process can be attributed to the harmful effects of aPDT to the cells, as demonstrated in the present study. It should be mentioned that a specific system for aPDT application in Endodontics (Helbo) was used in the present study, which allows a three-dimensional laser exposure to the full root canal length through a flexible optical fiber tip, which is expected to optimize the action of the light source. Additionally, the root canals were conditioned with a phenothiazine-based PS at $10 \mathrm{mg} / \mathrm{mL}$ concentration in a specific system for use in the root canal system (Helbo Blue). Phenothiazine dyes, whose basic structure is composed of a tricyclic aromatic ring, are the most commonly used and widely studied for aPDT, being activated by light in the 620 to $700 \mathrm{~nm}$ spectrum (red light) $[6,35,36]$. These dyes have a hydrophilic nature, low molecular weight and positive charge, which facilitate their penetration through the cell wall of Gram-negative bacteria $[8,14,37]$, causing irreversible damage to essential intracellular molecules including proteins, membrane lipids, and nucleic acids [37]. It is known that many commonly used PS lead to phototoxicity in Gram-positive species, which are efficiently inactivated by aPDT [11].

The results of this study were similar to those of previous studies from our research group, ie the use of aPDT in one root canal treatment session presented worse histopathological results than two-session endodontic treatment in the repair of teeth with pulp necrosis and apical periodontitis even when using a specific system for delivering light and PS inside the root canals. This difference using aPDT may be due to the harmful effects caused to the host cells, perhaps related to the light intensity and the PS. Thus, it is suggested that additional studies are conducted to determine the effect of aPDT used with different parameter settings in healthy tissue with no infection. 
Currently, a study is in progress to test different dilutions of the dye and different exposure times of the laser on the subcutaneous cavity of mice. This will hopefully determine the best dilution and exposure time of the light to obtain less damage to the healthy tissues.

Furthermore, in the present study, apical closure by deposition of mineralized tissue after endodontic treatment was not achieved in either of the groups treated with aPDT and the percent reduction of the periapical lesion size was significantly lower compared with the group medicated with a $\mathrm{CH}$-based dressing.

In view of the methodology used and the results obtained, it may be concluded that although the aPDT has shown promising results, its results in the present study were worse than those obtained with two-session endodontic treatment using a $\mathrm{CH}$-based dressing in teeth with pulp necrosis and apical periodontitis.

Acknowledgements

This study was supported by grants from The São Paulo State Foundation/FAPESP (Grants: \#2012/10238-1 and 2012/14505).

Conflict of Interest

The authors declare that they have no conflict of interest.

\section{References}

1. Nair PNR (2004) Pathogenesis of apical periodontitis and the causes of endodontic failures. Crit Rev Oral Biol Med 15:348-381.

2. Gomes BP, Pinheiro ET, Gadê-Neto CR, et al (2004) Microbiological examination of infected dental root canals. Oral Microbiol Immunol 19:71-76.

3. Sathorn C, Parashos P, Messer H (2009) Australian endodontists' perceptions of single and multiple visit root canal treatment. Int Endod J 42:811-818. 
4. Vera J, Siqueira JF Jr, Ricucci D, et al (2012) One- versus two-visit endodontic treatment of teeth with apical periodontitis: a histobacteriologic study. J Endod 38:1040-1052.

5. Silva LA, Novaes AB Jr, de Oliveira RR, Nelson-Filho P, Santamaria M Jr, Silva RA (2012) Antimicrobial photodynamic therapy for the treatment of teeth with apical periodontitis: a histopathological evaluation. J Endod 38:360-366.

6. Gursoy H, Ozcakir-Tomruk C, Tanalp J, et al (2013) Photodynamic therapy in dentistry: a literature review. Clin Oral Investig 17:1113-1125.

7. Chrepa V, Kotsakis GA, Pagonis TC, Hargreaves KM (2014) The effect of photodynamic therapy in root canal disinfection: a systematic review. J Endod 40:891-898.

8. Trindade AC, De Figueiredo JA, Steier L, Weber JB (2015) Photodynamic therapy in endodontics: a literature review. Photomed Laser Surg 33:175-182.

9. Borsatto MC, Correa-Afonso AM, Lucisano MP et al (2015) One-session root canal treatment with antimicrobial photodynamic therapy (aPDT): an in vivo study. Int Endod J doi: 10.1111/iej.12486.

10. Konopka KE, Goslinski T (2007) Photodynamic therapy in dentistry. J Dent Res $86: 694-707$.

11. Hamblin MR, Hasan T (2004) Photodynamic therapy: a new antimicrobial approach to infectious disease? Photochem Photobiol Sci 3:436-450.

12. Soukos NS, Chen PS, Morris JT, et al (2006) Photodynamic therapy for endodontic disinfection. J Endod 32:979-984.

13. Foschi F, Fontana CR, Ruggiero K, et al (2007) Photodynamic inactivation of Enterococcus faecalis in dental root canals in vitro. Lasers Surg Med 39:782787. 
14. Fimple JL, Fontana CR, Foschi F, et al (2008) Photodynamic treatment of endodontic polymicrobial infection in vitro. J Endod 34:728-734.

15. Garcez AS, Nuñez SC, Hamblin MR, Ribeiro MS (2008) Antimicrobial effects of photodynamic therapy on patients with necrotic pulps and periapical lesion. $\mathbf{J}$ Endod 34:138-142.

16. Garcez AS, Nuñez SC, Hamblim MR, Suzuki H, Ribeiro MS (2010) Photodynamic therapy associated with conventional endodontic treatment in patients with antibiotic-resistant microflora: a preliminary report. J Endod $36: 1463-1466$.

17. Ng R, Singh F, Papamanou DA, et al (2011) Endodontic photodynamic therapy ex vivo. J Endod 37:217-222.

18. Meire MA, Coenye T, Nelis HJ, De Moor RJ (2012) Evaluation of Nd:YAG and Er:YAG irradiation, antibacterial photodynamic therapy and sodium hypochlorite treatment on Enterococcus faecalis biofilms. Int Endod J 45:482491.

19. Yildirim C, Karaarslan ES, Ozsevik S, Zer Y, Sari T, Usumez A (2013) Antimicrobial efficiency of photodynamic therapy with different irradiation durations. Eur J Dent 7:469-473.

20. Xhevdet A, Stubljar D, Kriznar I, et al (2014) The disinfecting efficacy of root canals with laser photodynamic therapy. J Lasers Med Sci 5:19-26.

21. da Frota MF, Guerreiro-Tanomaru JM, Tanomaru-Filho M, Bagnato VS, Espir CG, Berbert FL (2015) Photodynamic therapy in root canals contaminated with Enterococcus faecalis using curcumin as photosensitizer. Lasers Med Sci 30:1867-1872. 
22. Bago Jurič I, Plečko V, Anić I, et al (2016) Antimicrobial efficacy of photodynamic therapy, Nd:YAG laser and QMiX solution against Enterococcus faecalis biofilm. Photodiagnosis Photodyn Ther 13:238-243.

23. Bouillaguet S, Wataha JC, Zapata O, Campo M, Lange N, Schrenzel J (2010) Production of reative oxygen species from photosensitizers activated with visible light sources available in dental offices. Photomed Laser Surg 28:519525.

24. Garcez AS, Fregnani ER, Rodriguez HM, et al (2013) The use of optical fiber in endodontic photodynamic therapy. Is it really relevant? Lasers Med Sci 28:79-85.

25. Standards ISO (1997) ISO 7405: preclinical evaluation of biocompatibility of medical devices used in dentistry-tests methods for dental materials. International Organization for Standardization Geneva, Switzerland.

26. Anić I, Tachibana H, Masumoto K, Qi P (1996) Permeability, morphologic and temperature changes of canal dentine walls induced by Nd: YAG, $\mathrm{CO} 2$ and argon lasers. Int Endod J 29:13-22.

27. da Silva LA, Nelson-Filho P, da Silva RA, et al (2010) Revascularization and periapical repair after endodontic treatment using apical negative pressure irrigation versus conventional irrigation plus triantibiotic intracanal dressing in dogs' teeth with apical periodontitis. Oral Surg Oral Med Oral Pathol Oral Radiol Endod 109:779-787.

28. Bezerra da Silva RA, Nelson-Filho P, Lucisano MP, De Rossi A, de Queiroz AM, Bezerra da Silva LA (2014) MyD88 knockout mice develop initial enlarged periapical lesions with increased numbers of neutrophils. Int Endod J 47:675686. 
29. Cohenca N, Romualdo PC, da Silva LA, et al (2015) Tissue response to root canal irrigation systems in dogs' teeth with apical periodontitis. Clin Oral Investig 19:1147-1156.

30. da Silva LA, da Silva RA, Branco LG, Navarro VP, Nelson-Filho P (2008) Quantitative radiographic evaluation of periapical bone resorption in dog's teeth contaminated with bacterial endotoxin (LPS) associated or not with calcium hydroxide. Braz Dent J 19:296-300.

31. Paula-Silva FW, Ghosh A, Arzate H, Kapila S, da Silva LA, Kapila YL (2010) Calcium hydroxide promotes cementogenesis and induces cementoblastic differentiation of mesenchymal periodontal ligament cells in a CEMP1- and ERK-dependent manner. Calcif Tissue Int 87:144-157.

32. Desai S, Chandler N (2009) Calcium hydroxide-based root canal sealers: a review. J Endod 35:475-480.

33. Kranz S, Guellmar A, Völpel A, Gitter B, Albrecht V, Sigusch BW (2011) Photodynamic suppression of Enterococcus faecalis using the photosensitizer mTHPC. Lasers Surg Med 43:241-248.

34. Siqueira JF Jr, Rôças IN (2011) Optimising single-visit disinfection with supplementary approaches: a quest for predictability. Aust Endod J 37:92-98.

35. Harris F, Chatfield LK, Phoenix DA (2005) Phenotiazinium based photosensitizers: photodynamic agents with a multiplicity of cellular targets and clinical applications. Curr Drug Targets 6:615-627.

36. Garcia V, Longo M, Fernandes LA, et al (2014) Effect of the concentration of phenotiazine photosensitizers in antimicrobial photodynamic therapy on bone loss and the immune inflammatory response of induced periodontitis in rats. $\mathbf{J}$ Periodontol Res 49:584-594. 
37. Upadya MH, Kishen A (2010) Influence of bacterial growth modes on the susceptibility to light-activated disinfection. Int Endod J 43:978-987. 

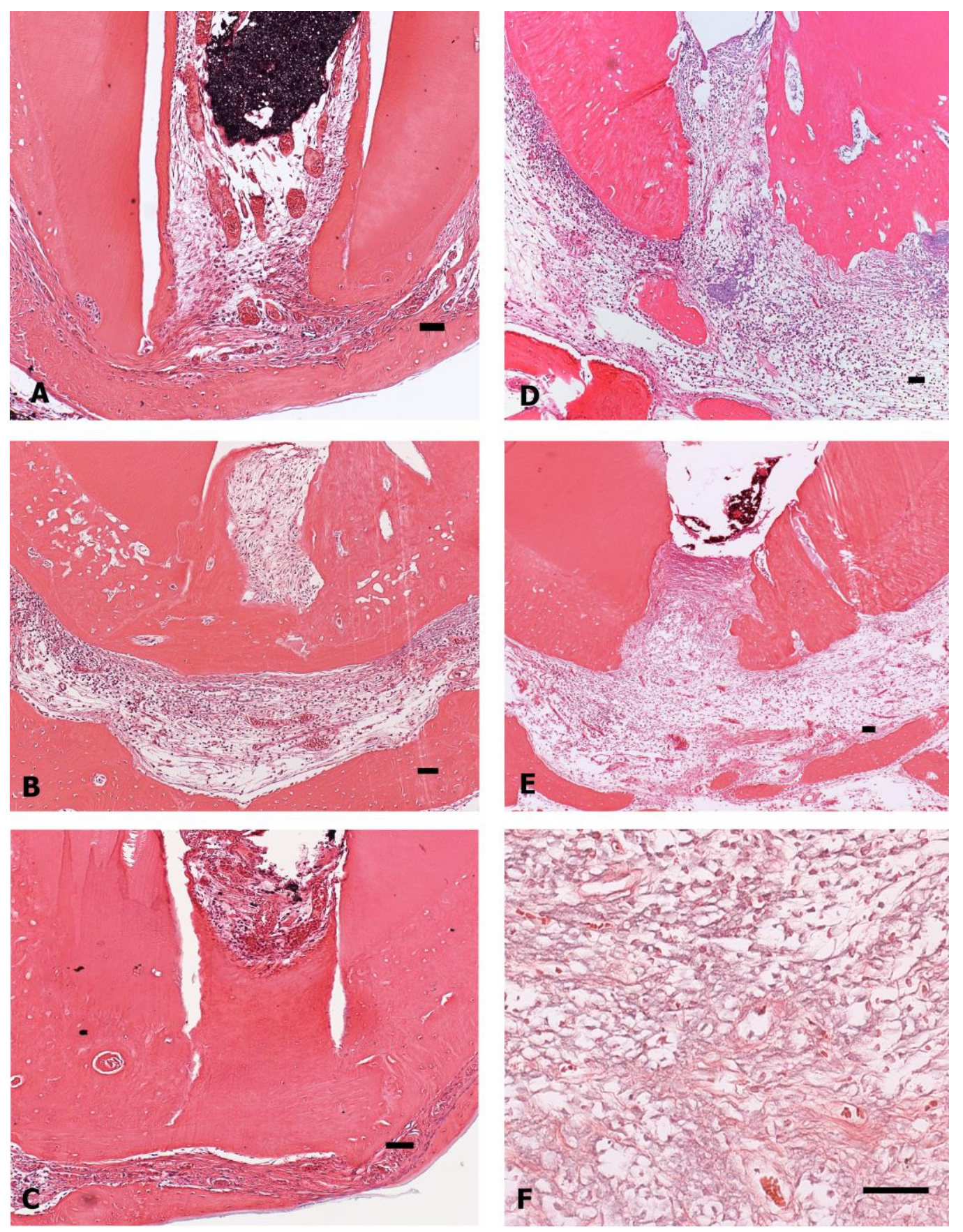

Figura 1. Photomicrographs of representative HE-stained microscopic sections. Panels on the left column represent Groups I and III. Panels on the right column represent Groups II and IV. (A) Panoramic view of the root apex showing normal periodontal ligament, absence of inflammatory cells, and initial biological sealing. (B) Root apex region showing intense formation of newly formed apical mineralized tissue. Periodontal ligament with mild presence of inflammatory cells. Alveolar bone with intense presence of osteoblasts in the bone surface. (C) Presence of biological apical sealing. Normal periodontal ligament and alveolar bone showing final stage of healing. (D) Root apex region showing unrepaired resorption areas. Moderately increased periodontal ligament with mild presence of inflammatory cells. (E) Root apex region showing absence of biological apical sealing, presence of inflammatory cells and. (F) Intense fibrilar dissociation highlighted in a higher magnification. Scale Bars $=50 \mu \mathrm{m}$. 

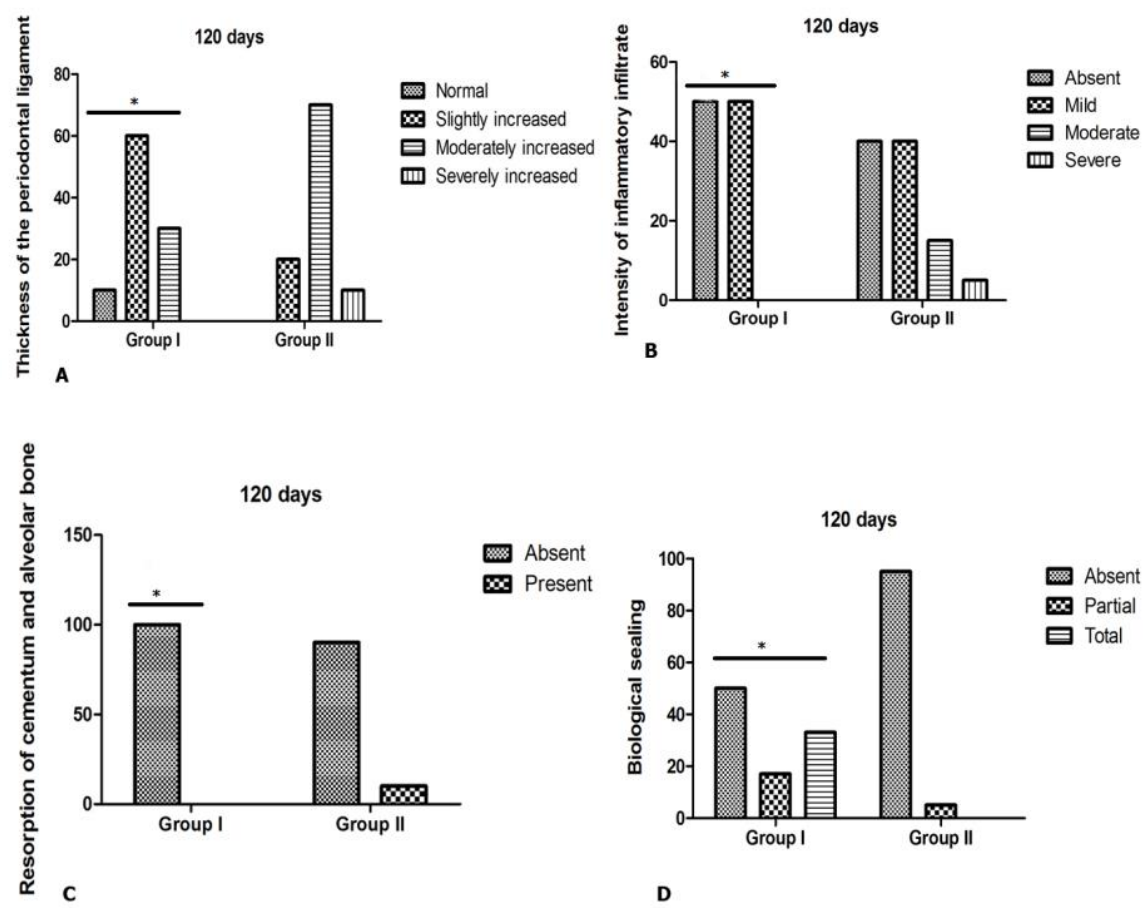

Figure 2. Graphic presentation of the 120-day results of the semi-quantitative (scores) analysis regarding periodontal ligament thickness (A), intensity of the inflammatory infiltrate (B), Cementum and alveolar bone resorption (C) and apical closure by deposition of mineralized tissue (D). * indicates statistically significant difference between the groups $(\mathrm{p}<0.05)$.
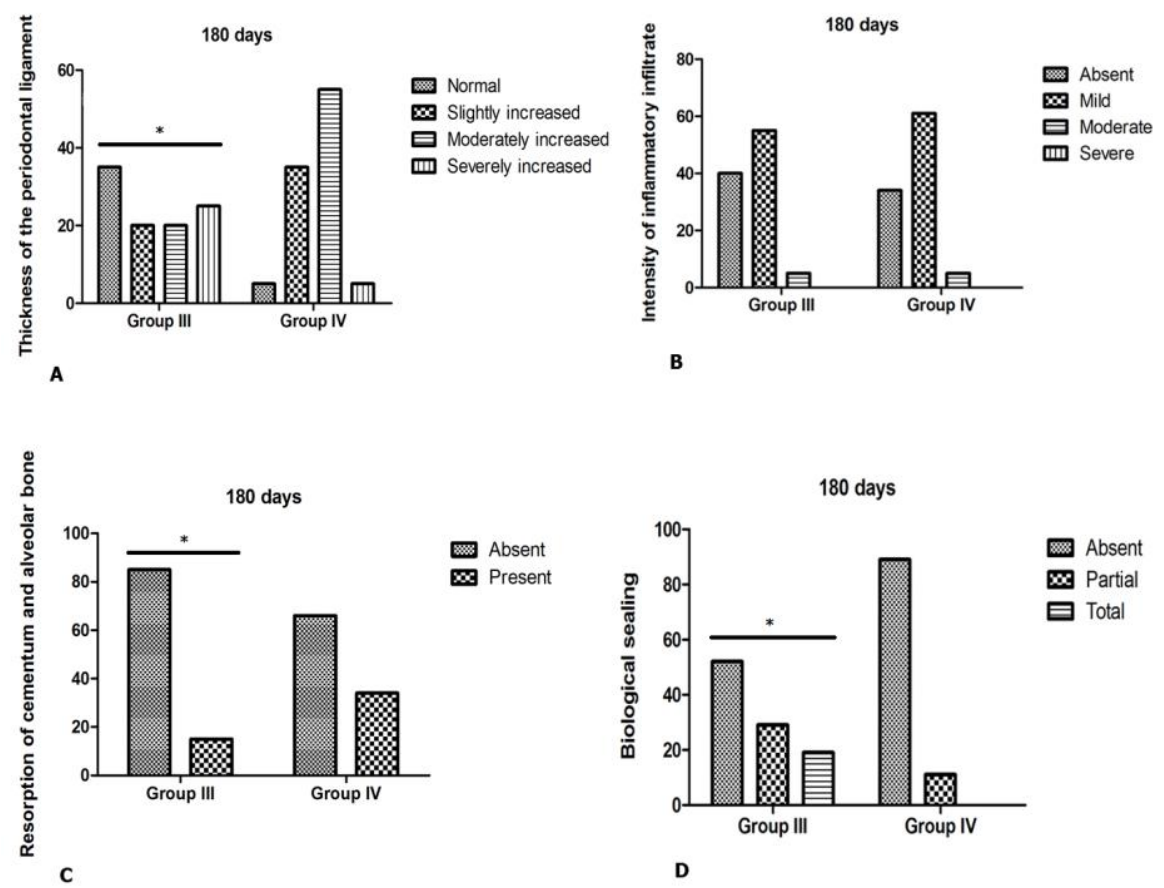

Figure 3. Graphic presentation of the 180-day results of the semi-quantitative (scores) analysis regarding periodontal ligament thickness (A), intensity of the inflammatory infiltrate (B), Cementum and alveolar bone resorption (C) and apical closure by deposition of mineralized tissue (D). * indicates statistically significant difference between the groups. 

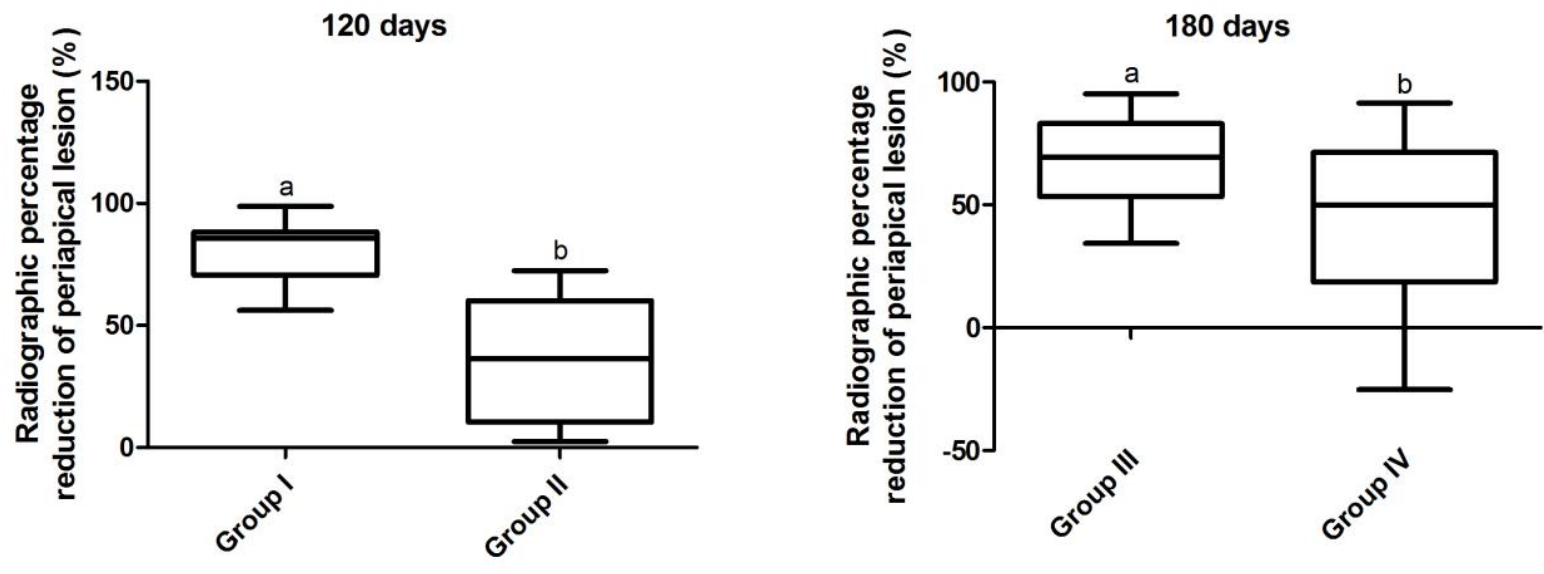

120 days

180 days
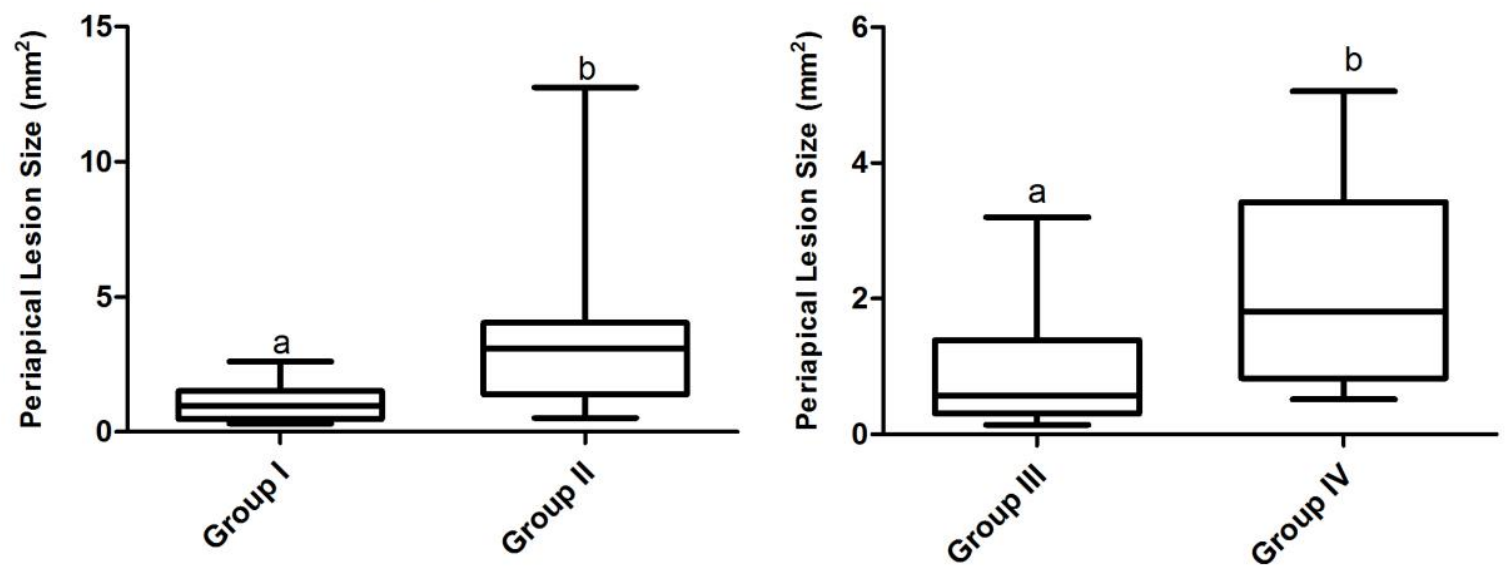

Figure 4. Box plot presenting minimum value, 1st quartile, median, 3rd quartile and maximum value, comparing the area of the periapical lesions ( $\mathrm{mm} 2$ ) observed under fluorescence microscopy (A and B) according to the two types of treatment (one-session root canal treatment with aPDT and two-session root canal treatment with a $\mathrm{CH}$ based antibacterial dressing), after 120 days (A) and 180 days (B).

Box plot presenting minimum value, 1st quartile, median, 3rd quartile and maximum value, comparing the percentage of periapical lesion size reduction (C and D) according to the two types of treatment (one-session root canal treatment with aPDT and two-session root canal treatment with a $\mathrm{CH}$-based antibacterial dressing), after 120 days (C) and 180 days (D). Different letters indicate statistically significant difference. 


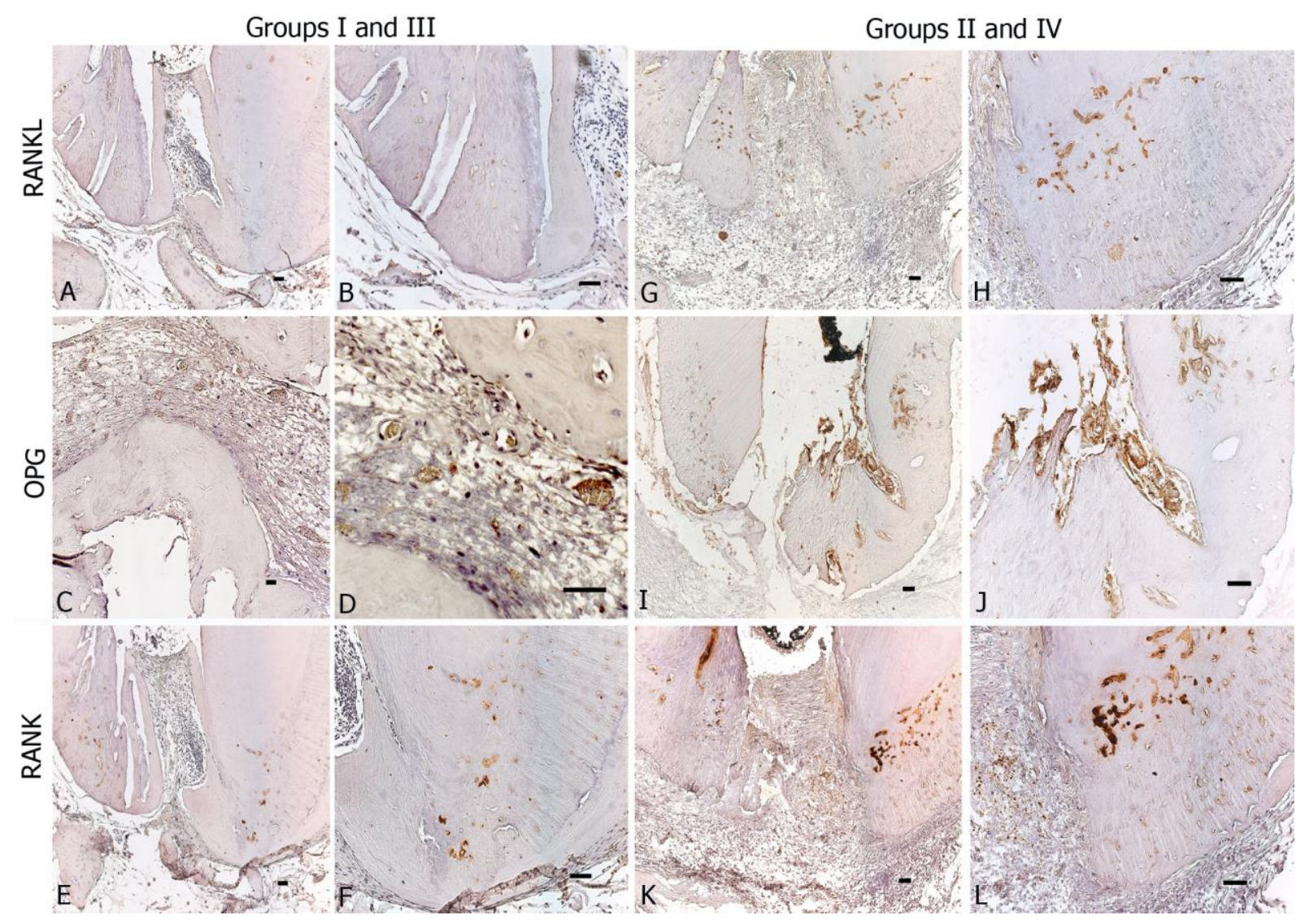

Figure 5. Representative photomicrographs of dog's teeth stained by immunohistochemistry for the identification of osteoclastogenesis markers RANKL, OPG, and RANK. Panels on the left columns (A-F) represent Groups TS/CH120d and TS/CH180d. Panels on the right columns (G-L) represent Groups OS/aPDT120d and OS/aPDT180d. Scale Bars $=50 \mu \mathrm{m}$. 
